\title{
EL CASTILLO DE HERCE EN EL VALLE DEL CIDACOS. UNA MIRADA HISTÓRICO-ARTÍSTICA
}

\author{
Minerva Sáenz Rodríguez \\ Universidad de La Rioja
}

\begin{abstract}
RESUMEN: La restauración del castillo de Herce se hizo realidad tras un proceso desarrollado entre los años 2006 y 2009, el cual incluyó, aparte de la propia intervención, una serie de trabajos previos: un proyecto arquitectónico, un estudio histórico-artístico y una excavación arqueológica. Tras una contextualización histórica del monumento, en la que se relaciona con otros similares de la zona, en este artículo se analiza su evolución histórica, su cronología y sus principales características tipológicas y constructivas. Las primeras citas documentales de fortalezas en Herce datan de 1200 y 1246 pero los restos conservados en el Cerro de El Salvador nos indican que su cronología no puede retrotraerse más allá del siglo XIII, de lo que se deduce que con anterioridad hubo otro castillo, como indican también los escasos restos materiales encontrados en las excavaciones. El de Herce, por tanto, no se construyó ex novo en la Baja Edad Media, sino que tuvo que sustituir a otro anterior altomedieval, relacionado con las luchas de conquista y reconquista entre musulmanes y cristianos. En cuanto a tipología, es uno de los prototipos de castillo montano, roquero, roqueño o topográfico, aunque más que un castillo propiamente dicho fue una atalaya, torre fuerte, vigía, de vigilancia, de señales u óptica.
\end{abstract}

Palabras clave: Herce, valle del Cidacos, Rioja Baja, restauración, Edad Media, castillo, arquitectura militar.

\section{HERCE CASTLE IN CIDACOS VALLEY: A HISTORICAL-ARTISTIC LOOK}

ABSTRACT: The restoration of Herce castle became a reality after a development process between 2006 and 2009; apart from the intervention itself, the process included a series of previous works: an architectural project, a historical-artistic study and an archaeological excavation. After a historical 
context of the monument, which is associated with similar ones in the area, this article analyzes the historical evolution, its chronology and its main typological and constructive features. The earliest documentary quotes of fortress in Herce date from 1200 and 1246, but the preserved remains in El Salvador Hill -as it shows the few found remains in excavations- indicate that its chronology can not go back beyond XIII century. Therefore, Herce castle was not built ex novo in the late Middle Ages, but it had to replace a previous high medieval one, which is related to the struggles of conquest and reconquest between Muslims and Christians. As for typology, it is one of the prototypes of mountain castle, rock castle, or topographical castle, although more than a castle itself, it was a watch tower, a fortress, or a signals or optical tower.

Keywords: Herce, Cidacos Valley, Rioja Baja, restoration, Middle Ages, castle, military architecture.

\section{Introducción}

Este artículo es un resumen del informe histórico-artístico que realicé en el año 2006 por encargo del Ayuntamiento de Herce, ante los trabajos de restauración que se iban a llevar a cabo en el conjunto patrimonial formado por el castillo de la localidad y la ermita de El Salvador, situada en sus proximidades, hacia el sudeste (Fig. 1, Láms.1-3). La excavación arqueológica previa a la intervención la realizó el arqueólogo David Eguizábal León, el proyecto de ejecución y levantamiento planimétrico lo redactó la arquitecta Georgina Martina Somer, y la propia intervención corrió a cargo del arquitecto Ramón Ruiz Marrodán, dándose por finalizado todo el proceso en 2009.

La problemática de cada castillo es diferente en función de las características de su arquitectura y de su estado de ruina, de ahí que también las actuaciones tengan que ser diversas y adecuadas a sus peculiaridades. En los Ilamados castillos roqueños o roqueros, ubicados en alto y en zonas de difícil acceso, que en la mayoría de los ejemplos sólo conservan algunos lienzos de muralla o restos de torres, -como ocurre en Herce-, sólo pueden consolidarse sus ruinas y protegerlas con el único fin de disfrutar de ellas o, en todo caso, del paisaje que se divisa desde sus estratégicos enclaves, convirtiéndolos en privilegiados miradores. En casos como éste las intervenciones son únicamente de rehabilitación, pues no se pueden aplicar soluciones más atrevidas que supondrían una refuncionalización o cambio de su función primitiva al destinarlos a un uso público, por ejemplo. El ejemplo más representativo de este tipo de actuaciones en La Rioja es el castillo de Aguas Mansas de Agoncillo, convertido en el Ayuntamiento de la localidad. Cada castillo merece, por tanto, una restauración diferente de- 
pendiendo de su destino final: protección y rehabilitación únicamente, o protección y refuncionalización para un nuevo uso.

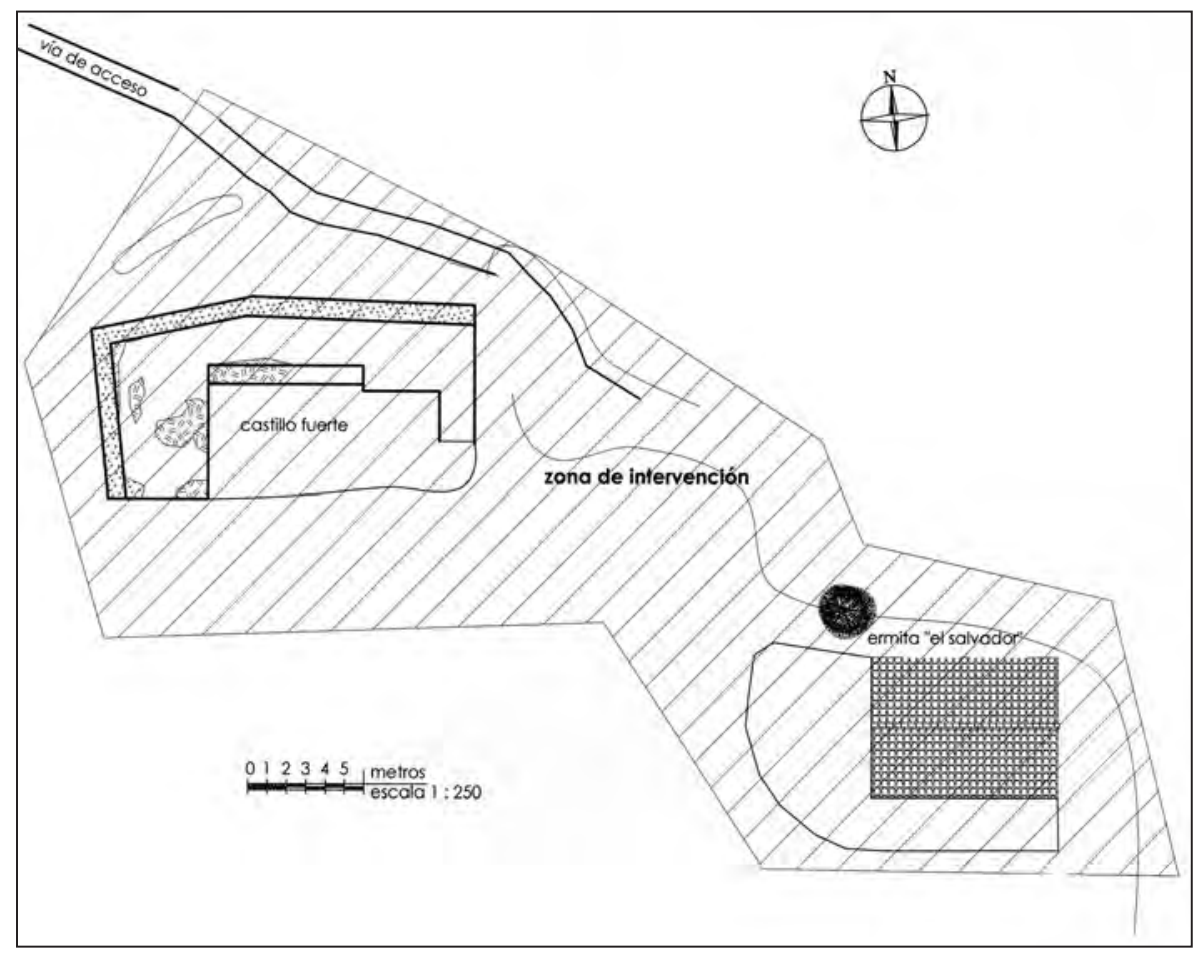

Figura 1. Herce. Castillo y ermita de El Salvador. Planta general de la zona de intervención. Plano de Georgina Martina Somer.

El estado de la cuestión del castillo de Herce se reduce a breves menciones en algunas obras, sin que hasta el momento se haya estudiado concienzudamente. Goicoechea (1949) o Establés Elduque (1993), no lo citan¹. Sí aparece en el Inventario artístico de la región (1976)², en el estudio dirigido por Moya Valgañón, Ruiz-Navarro Pérez y Arrúe Ugarte (1992)³ y en el inventario que poco

1. GOICOECHEA, C., Castillos de La Rioja. Notas descriptivas e históricas. Logroño, IER, 1949. ESTABLÉS ELDUQUE, J. Mạ Castillos de La Rioja. León, Ediciones Lancia, 1993.

2. MOYA VALGAÑ̃́N, J. G., (y otros), Inventario artístico de Logroño y su provincia. Tomo II: Cenicero-Montalbo en Cameros. Madrid, Ministerio de Educación y Ciencia, 1976, p. 196.

3. MOYA VALGAÑón, J. G., RUIZ-NAVARRO PÉREZ, J., ARRÚE UGARTE, B., Castillos y Fortalezas de La Rioja. Logroño, Caja de Ahorros de La Rioja, 1992, pp. 145-146. 
después realizó Sáenz de Pipaón Ibáñez (1996) También se alude a él esporádicamente en otras obras de carácter menos científico, como la Enciclopedia dirigida por Martín Losa $(1983)^{5}$, y la obra de Solano Antoñanzas sobre el valle del Cidacos $(1998)^{6}$, sin olvidar que Cooper (1991) incluye en su monumental trabajo algunos documentos en relación con la construcción de fortalezas en la villa ${ }^{7}$. En 1990 el Instituto de Estudios Riojanos dedicó sus II Jornadas de Arte Riojano a los castillos de la región ${ }^{8}$, cuyos resultados fueron publicados en la revista Brocar, del entonces Colegio Universitario de La Rioja9 ${ }^{9}$. En estas actas existen artículos sobre ámbitos concretos, como el de Cabañero Subiza sobre los castillos más primitivos $(1990)^{10}$, o el de Castellano Huerta sobre los de la Sierra de Cameros ${ }^{11}$. Tampoco pueden dejarse de lado los que estudian monográficamente los de Agoncillo, Leiva, Sajazarra, San Vicente de la Sonsierra, Briones, Clavijo, Arnedo, Quel, Autol, Cornago, torreón de Haro y restos del de Logroño, algunos publicados en las citadas actas y otros en artículos de prensa y en revistas especializadas.

En el año 2003, la Asociación Española de Amigos de los Castillos en La Rioja intentaba conseguir un futuro Plan Director de Castillos bajo el patrocinio del Gobierno Regional, el Colegio de Arquitectos y la Fundación Dinastía Vivanco. Arquitectos, historiadores y arqueólogos comenzaron a preparar una base documental, que sería la antesala de ese futuro Plan Director, para prever futuras restauraciones de los más urgentes, entre los que se incluían cuarenta. Este trabajo pretendía obtener una descripción de su arquitectura y de su estado físico, para, pos-

4. SÁENZ DE PIPAÓN IBÁÑEZ, Mํㅡㄹ C., Inventario de fortalezas, castillos y recintos amurallados en La Rioja. Ayuda para estudios científicos de temática riojana concedida por el Instituto de Estudios Riojanos en 1995. Logroño, IER, 1996. Inédito, pp. 62-63.

5. MARTín LOSA, F. (Director), y otros, Enciclopedia de La Rioja. Tomo 2. Logroño, Caja de Ahorros de Zaragoza, Aragón y Rioja, 1983, p. 90.

6. SOLANO ANTOÑANZAS, J. Mํㅡㄹ El valle del Cidacos (cuenca del Ebro).Vol. II. Los afluentes desde el nacimiento del río Cidacos, sus acequias, barrancos, arroyos, embalses o pantanos, molinos, fuentes, etc., con sus poblaciones y nacimientos. Calahorra, autor-editor, 1998, p. 265.

7. COOPER, E., Castillos Señoriales en la Corona de Castilla. Vol. II, Salamanca, Junta de Castilla y León, Ediciones Universidad de Salamanca, 1991, doc. núm. 208, pp. 1055-1056.

8. II Jornadas de Arte Riojano. Iniciación al Estudio de la Arquitectura Militar en La Rioja. La Rioja, 30 de noviembre, 1 y 2 de diciembre de 1990. Organiza y patrocina: Departamento de Arte del IER. Colaboran: Asociación Española de Amigos de los Castillos y Colegio Oficial de Arquitectos de La Rioja.

9. Cuadernos de Investigación Histórica Brocar, núm. 16, diciembre, 1990, Logroño, CUR, 1991.

10. CABAÑERO SUBIZA, B., "Los castillos en La Rioja construidos frente al dominio del Islam. Notas sobre su origen". Cuadernos de Investigación Histórica Brocar, núm. 16, diciembre, 1990, Logroño, CUR, 1991, pp. 19-40.

11. CASTELLANO HUERTA, Ma A., "La fortificación militar medieval en la sierra de los Cameros". Cuadernos de Investigación Histórica Brocar, núm. 16, diciembre 1990, Logroño, CUR, 1991, pp. 41-49. 
teriormente, poder recuperarlos y conservarlos ${ }^{12}$. Parte de esta base documental, en la que se recogían los informes arquitectónicos y planimétricos de veinte de los cuarenta castillos incluidos en el proyecto, fue presentada en 2004. De los siete del valle del Cidacos se incluían cinco: Enciso, Arnedillo, Préjano, Herce y Quel; los dos restantes, Arnedo y Autol, formaban parte de otro grupo de veinte cuyos informes se presentarían al año siguiente. Al final de todo ello se elaboraría el Plan Director que detallaría las actuaciones concretas a realizar en cada uno ${ }^{13}$. En 2005 se comenzó a actuar en el castillo de Cornago y en su entorno, en el que se sitúa la iglesia de San Pedro, bajo un proyecto promovido por el Ayuntamiento de la localidad y con la ayuda económica de la Asociación para el Desarrollo de La Rioja Suroriental, que gestiona el programa Leader Plus ${ }^{14}$.

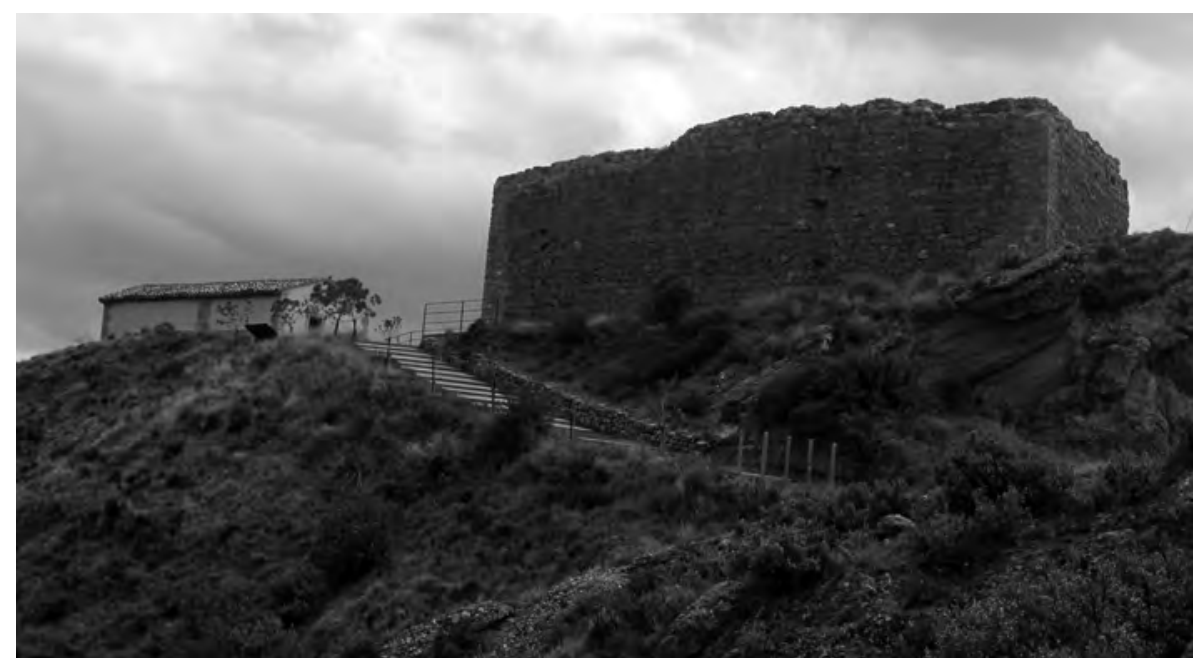

Lámina 1. Castillo y ermita de El Salvador desde el norte, tras la intervención arquitectónica.

El caso del castillo de Herce fue similar, iniciándose el proceso en 2006 y finalizándose en 2009. Partiendo de una iniciativa del Ayuntamiento y con la ayuda económica del Leader Plus, se pretendía actuar en este conjunto monumental que, como el de Cornago, está formado por dos elementos arquitectónicos, uno de carácter militar y otro religioso, aunque en este caso mucho más modestos: los restos

12. BLANCO, B., "La Asociación de Amigos de los Castillos trabaja para conseguir un futuro Plan Director". La Rioja. Logroño, 30-marzo-2003, pp. 58-59.

13. P. M. G., "La Rioja presenta la base documental para proteger veinte de sus cuarenta castillos". La Rioja. Logroño, 17-febrero-2004, pp. 48-49. J. L. D., "La Rioja tendrá a fin de año un inventario preciso sobre el estado de sus 40 castillos". El Correo, 17-febrero-2004, p. 5.

14. REDACCIÓN EDITORIAL, "Cornago. Importantes actuaciones en el castillo durante este año 2005". El Eco de La Rioja. 8-abril-2005, p. 11. 
de una torre fuerte con su muralla defensiva y una pequeña ermita. La intervención estaba motivada por una tradición de carácter popular: facilitar las romerías que se celebran en el mes de mayo a dicha ermita en torno al día de la Ascensión, y que atraen al lugar a numerosos fieles, ocupando en sus idas y venidas el espacio del castillo. El proyecto consistió básicamente en consolidar las ruinas del mismo convirtiéndolas en un mirador del valle del Cidacos y de sus sierras, y en acondicionar su entorno para crear un espacio más accesible y menos peligroso. El objetivo final fue crear un conjunto arquitectónico y paisajístico que integrara ambos elementos (castillo y ermita), tanto para recuperar el propio conjunto patrimonial como para potenciar su desarrollo turístico, pues a la vez que se facilitaba la celebración de la romería, se podrían organizar otras actividades con los pueblos cercanos en relación con la ruta de los castillos del Cidacos ${ }^{15}$.

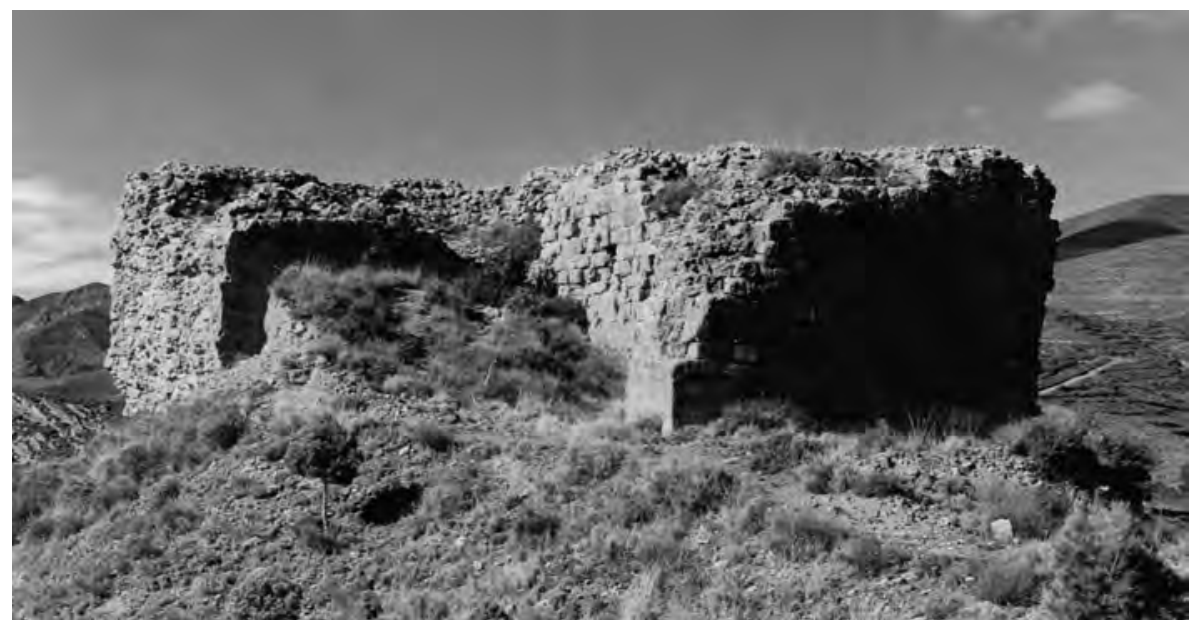

Lámina 2. Castillo sobre el Cerro de El Salvador desde el sudeste, antes de su restauración.

15. Los resultados del informe histórico-artístico realizado sobre el castillo de Herce, fueron expuestos parcialmente en mi intervención como ponente el 15 de mayo de 2009 en la mesa redonda: "Recuperación del castillo de Herce y su entorno", dentro de las Jornadas culturales (Historia del castillo y su recuperación), celebradas del 14 al 17 de mayo de 2009 en Herce, y organizadas por el Ayuntamiento de la localidad. También en la conferencia que impartí en Herce el 7 de mayo de 2010, sobre: "El patrimonio histórico-artístico de Herce y su proyección turística", dentro de las II Jornadas culturales. Paisaje y patrimonio, Herce ante el desafío de un nuevo turismo cultural, celebradas el 6 y 7 de mayo de 2010 en Herce, y organizadas asimismo por el Ayuntamiento. El 22 de noviembre de 2011 expuse una aproximación general al tema de la recuperación de los castillos del Cidacos, junto con el arqueólogo Juan Manuel Tudanca Casero y el arquitecto Óscar Reinares Fernández, en la mesa redonda: "Historia, Arqueología y Arquitectura de los castillos del Cidacos: aspectos relevantes de un patrimonio singular", dentro de las II Jornadas sobre castillos de La Rioja. Los castillos del Cidacos: pasado, presente y futuro, celebradas del 22 al 24 de noviembre de 2011 en Arnedo, y organizadas por la Asociación de Amigos de los Castillos de La Rioja y la Fundación Cajarioja. 


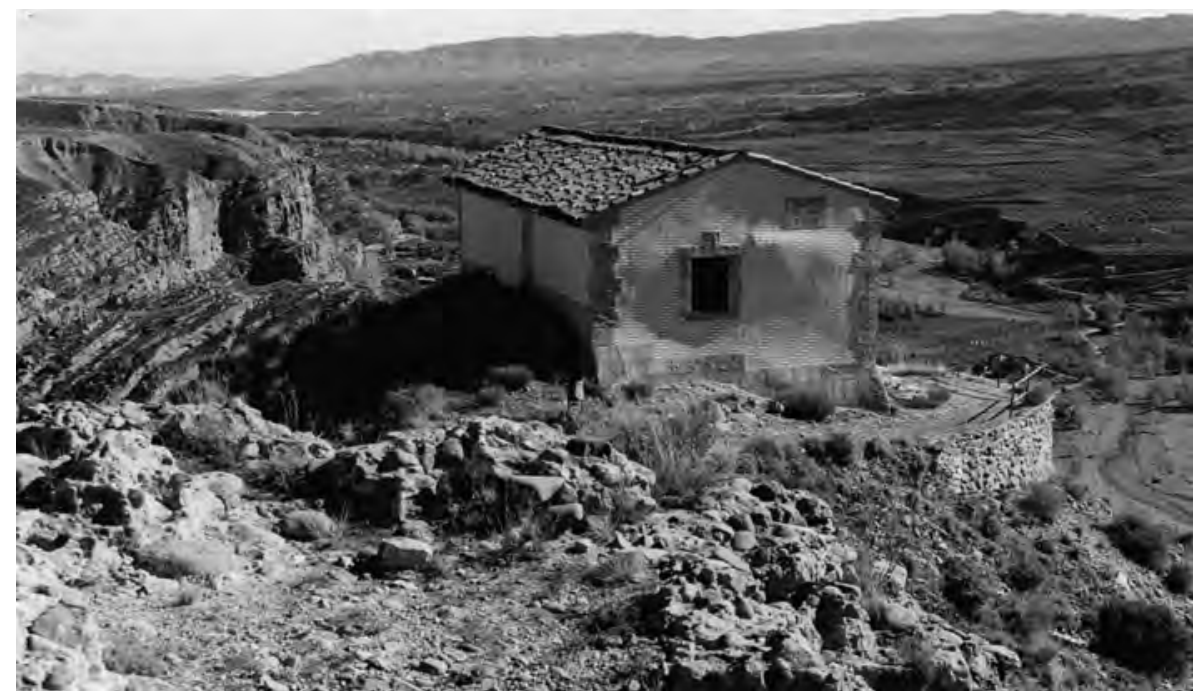

Lámina 3. Ermita de El Salvador y, en primer plano, remate superior del muro oriental del castillo.

A finales del 2009, a los pocos meses de la finalización de las obras en Herce, tuvo lugar la firma del convenio "Declaración de Aguas Mansas" en el castillo de Agoncillo, entre la Consejería de Educación, Cultura y Deporte del Gobierno de La Rioja y los alcaldes de los siete municipios con castillos del valle del Cidacos. Este convenio fue la materialización de todo el proyecto, por el que los ayuntamientos implicados se comprometieron a destinar parte de sus presupuestos para la restauración de sus fortalezas, siempre asesorados y coordinados por la Asociación de Amigos de los Castillos de La Rioja.

\section{La castellología medieval en La Rioja}

Los castillos de nuestra región son, al menos en su origen, símbolo de las continuas guerras que se produjeron durante ocho siglos entre los reinos musulmanes de Al-Andalus y los de la Hispania cristiana. La mayoría surgieron, por tanto, entre los siglos VIII y XV, época de la dominación musulmana, con distintas finalidades: para defenderse del enemigo (unas veces cristiano y otras árabe), para proteger a la población y para mantener la conquista del territorio e impedir que fuera arrebatado por unos o por otros ${ }^{16}$. Después, tras la reconquista, los castillos siguieron siendo el blanco de diversas contiendas, pero ya

16. MARTíNEZ DE SALINAS y SALCEDO, J. L., "Al asalto de los castillos". La Rioja Domingo, Logroño, 27-abril-1997, p. IV. 
entre los distintos reinos cristianos (navarros y castellanos en nuestro caso), enfrentados por asuntos territoriales.

En época del califato de Córdoba (912-1031), los musulmanes organizaron un sistema de fortalezas que, unidas a las cercas de las ciudades, defendían el interior de $\mathrm{Al}$-Andalus contra los ataques de los cristianos ${ }^{17}$. Por su parte, los reinos del norte peninsular también tuvieron que fortificarse por estar desde su origen continuamente sometidos a cambios territoriales motivados por las diferentes contiendas de conquista y reconquista, y por la repoblación, la expansión feudal y la reorganización política de las monarquías, primero asturiana y después leonesa, castellana, navarra, etc. Las primeras líneas aparecen en todos estos reinos motivadas por la inevitable defensa de ese límite meridional entre musulmanes y cristianos, frontera siempre fluctuante, imprecisa y cambiante, pues continuamente se desplazaba más hacia el sur. La reconquista y la repoblación de las tierras ocupadas requería esa potente organización militar a base de castillos que aseguraran el control del territorio, cuya rápida proliferación daría lugar al nombre de Castilla ${ }^{18}$.

La Rioja, integrada en la provincia visigoda de Cantabria, fue conquistada por los árabes, capitaneados por las tropas de Musa ben Nusayr, en el año 714. El valle del Cidacos y gran parte de la región no se reconquistaron hasta la segunda década del siglo X. Tras la caída de los Banu Qasi o de los Muza, cuyo dominio sobre el valle del Ebro y muy especialmente sobre la zona de Arnedo terminó a partir del 92319, se reconquistó Nájera, Viguera y posiblemente Arnedo, mediante la alianza del rey de Asturias Ordoño II y el de Pamplona Sancho Garcés I. Calahorra no se tomó hasta el año 1045 tras una ofensiva de García el de Nájera, y fue entonces cuando toda la zona más occidental de La Rioja hasta el valle del Cidacos quedó definitivamente en manos cristianas, pasando a formar parte del reino de Pamplona hasta 1076, y del de Castilla a partir de esa fecha. Es en este periodo que abarca los siglos VIII al XI cuando la garganta del Cidacos cobra una importancia estratégica por ser la puerta a Valdearnedo o Valle de Arnedo, zona que controlaba la supuesta calzada romana que siguiendo el río, unía Numancia con Calahorra, o dicho de otro modo, las tierras del Duero con las del Ebro. Por tanto, hasta el siglo XI la comarca debió ser la avanzadilla de la frontera frente al Islam, que seguiría el curso medio y alto del Cidacos. Tras

17. TORRES BALBÁS, L., "Arte hispanomusulmán. Hasta la caída del califato de Córdoba", en MENÉNDEZ PIDAL, R. (Director), Historia de España. España musulmana hasta la caída del califato de Córdoba (711-1031 de J. C.). Tomo V, Madrid, Espasa-Calpe, 1973, p. 646.

18. GUTIÉRREZ GONZÁLEZ, J. A., "Castillos y sistemas de defensa en los reinos de León y Castilla". II Semana de Estudios Medievales. (Nájera, del 5 al 9 de agosto de 1991). Logroño, IER, 1992, pp. 31-32.

19. La familia muladí de los Banu Qasi fue inaugurada por el conde Casius, cristiano visigodo que se convirtió al Islam hacia el 715 para no perder sus tierras, tomando el nombre de Beni Qasi (o Banu Qasi), e inaugurando la estirpe de los Muza. El último miembro de esta familia murió en el 924. 
la pérdida de Calahorra, a los musulmanes les debió resultar difícil mantenerse en este valle.

En general, los reinos peninsulares del norte de España fueron pioneros en Europa durante el siglo $\mathrm{X}$ en sus investigaciones sobre los distintos aspectos de los castillos, creando en esta centuria todos los prototipos más importantes que tuvo en el futuro la arquitectura militar medieval. Algunas de estas primitivas fortalezas riojanas de frontera con restos musulmanes y cristianos primitivos, estudiadas por Cabañero Subiza ${ }^{20}$, son de difícil interpretación, pues como existe una identificación absoluta en algunas fórmulas de la castellología musulmana y cristiana, en muchas ocasiones es imposible discernir si fueron construidas por unos o por otros.

El sistema defensivo que hubo en el valle medio del Cidacos desde época altomedieval estaba formado por el castillo de Arnedo y las torres fuertes o atalayas de Préjano, Herce, Quel y Autol. Las de Enciso y Arnedillo formarían parte de esta misma línea defensiva y protegerían a esta zona, en principio bajo dominio musulmán, de las posibles incursiones cristianas desde la zona alta de la cuenca. Durante los siglos VIII al XIII la invasión árabe se extendió por las fértiles vegas de este valle, mientras que la resistencia cristiana se ocultó en las zonas serranas, más idóneas para defenderse, circunstancias históricas que quedaron reflejadas en estas construcciones ${ }^{21}$. Por tanto, todas ellas en origen serían fortalezas musulmanas edificadas en altura, denominadas hisn en árabe, y alcazabas en castellano ${ }^{22}$. Cuando es la residencia real se le llama alcázar, derivado del topónimo correlativo árabe.

Realmente, la reconquista de La Rioja fue costosa debido a la solidez del sistema defensivo establecido por los musulmanes en el Ebro, que entonces era la frontera superior. El gran número de fortalezas árabes existentes en esa zona (además de las ya citadas lo eran las de Cervera, Albelda, Clavijo y castillo de la Mota en Nájera), dificultó el avance cristiano, siendo la mayoría de ellas restauradas o totalmente reconstruidas por los cristianos después de haberlas conquistado ${ }^{23}$. De ese modo, los castillos más antiguos de La Rioja, aunque acabaron siendo fortalezas cristianas, son de origen musulmán. A pesar de que en la arquitectura militar sea difícil hablar de estilos artísticos, sus restos más antiguos

20. CABAÑERO SUBIZA, B., "Los castillos de la Rioja construidos frente al dominio del Islam. Notas sobre su origen". Cuadernos de Investigación histórica Brocar, núm. 16, diciembre 1990, Logroño, CUR, 1991, pp. 19-40.

21. MARTÍNEZ DE SALINAS y SALCEDO, J. L., "Quinta ruta de los castillos riojanos, por el valle del río Cidacos. La huella de la historia". La Rioja Domingo, Logroño, 31-agosto-1997, p. VI.

22. TORRES BALBÁS, L., Op. cit., p. 381, sigue al arabista francés Evarite Lévi-Provençal al utilizar esta terminología.

23. HERAS y NÚÑ̃EZ, Ma A. de las, Estructuras arquitectónicas riojanas. Siglos X al XIII. "Biblioteca de Temas Riojanos", Logroño, IER, Gobierno de La Rioja, 1986, p. 49. 
podrían datarse en los siglos X y XI, en esa época de transición entre lo prerrománico y lo románico. Los únicos que conservan restos del siglo $X$ son los de la Mota en Nájera (en ruina absoluta), Clavijo, Autol, Arnedo, Arnedillo y Enciso.

Hasta el primer cuarto del siglo X lo habitual fue el acondicionamiento de hábitats troglodíticos, tanto naturales como artificiales, y la construcción de incipientes fortalezas levantadas con materiales lígneos. De este modo, las cuevas y las galerías naturales fueron utilizadas como refugio. El acondicionamiento de cuevas para fortalezas queda demostrado en algunas del valle del Iregua (Viguera, citada en el 875, Islallana y Castañares de las Cuevas), y en otras del valle del Alhama (Cervera e Inestrillas). Son fortificaciones rupestres o "peñas bravas", contemporáneas de los eremitorios y poblamientos rupestres de su alrededor, que consisten en covachas naturales con corredores y habitaciones excavadas en la roca, protegidas por muros de tapial y mampostería con entramados de madera, y a veces refuerzos con torres almenadas (Inestrillas) o cadalsos (Viguera, Islallana y Castañares de las Cuevas). En cuanto a la utilización de materiales lígneos, está demostrado que las primeras defensas utilizadas contra el poder musulmán eran también meros fosos y empalizadas de madera, o incluso taludes de tierra dispuestos de manera provisional. Sobre estas motas artificiales de tierra, que eran como montículos de planta redondeada y que dieron lugar a algunos nombres de castillos como el de la Mota en Nájera, se podían realizar construcciones de tierra o piedra, que a veces se completaban con estructuras de madera adosadas a las propias paredes de la roca natural que se aprovechaba como fortaleza.

Pero hacia mediados del siglo $X$ las técnicas evolucionan y la utilización de la madera se va sustituyendo por el tapial, el encofrado de cal y canto, la tierra apisonada, y por último, la sillería de gran tamaño a soga y tizón al exterior, con argamasa, mortero o morrillo al interior. Por ejemplo, la fortaleza de Islallana estaba construida con tapial y madera (por las líneas de mechinales conservadas en la roca), la fortaleza de Autol es de tapial, y la de Enciso, de tierra apisonada, y su recinto exterior de tapial y mampostería. A veces, para dotar a los muros de tapial y encofrado de mayor resistencia, se colocaban en su interior de vigas de madera clavadas, técnica utilizada por ejemplo, en la torre mayor del castillo de Clavijo, donde todavía se pueden apreciar los restos de alguna de ellas, y en la torre de Arnedillo, donde también quedaron empotradas numerosas maderas en el muro para darle mayor solidez. La sillería de gran tamaño empieza a utilizarse a finales del siglo $X$ en el castillo de Nájera, y hacia las mismas fechas se intenta conseguir la torre circular hueca y los primeros cadalsos corridos. La torre circular se consigue en el castillo de Arnedo, pero es todavía maciza; la hueca se había dado en el mundo musulmán hacia el 925 (castillo de Olite) y en La Rioja aparece en escasos restos conservados en el de Nájera. La fórmula del cadalso corrido se halla en el de Arnedillo24.

24. CABAÑERO SUBIZA, B., Ibídem. 
Las primitivas fortalezas que se edificaron desde los siglos IX o X en las zonas de frontera entre cristianos y musulmanes suelen tener una tipología determinada. Son los llamados castillos montanos, roqueros, roqueños o topográficos, con fuerte influencia musulmana (de los hisn o alcazabas concretamente), de difícil acceso por su función exclusivamente defensiva y militar, como simple observatorio y refugio, no residenciales. Generalmente están ubicados en elevados macizos rocosos con buenas defensas naturales, rocas aisladas e inaccesibles con amplia visibilidad sobre la Ilanura, fuertes pendientes, planta irregular adaptada a la topografía, pequeñas construcciones a modo de torres atalayas en los puntos más elevados, y murallas que aprovechan también los resaltes rocosos del terreno. Su elevado emplazamiento permitía el dominio de las vías de comunicación de la zona ${ }^{25}$. Son de cantería por fuera y mampostería por dentro, y suelen tener muros rectos, torres redondas o cuadradas, torre del homenaje en el lugar más estratégico con entrada en alto a la que se accede con escalera móvil, almenas prismáticas, cadalsos cortos de madera, y puerta recta sin puente levadizo sino, en todo caso, con una pasarela móvil. Son castillos rudos, primitivos, de guarnición, prácticamente inhabitables, que nunca sirvieron de vivienda porque eran poco espaciosos, incómodos, enriscados y exentos de todo lujo, sin las más mínimas condiciones de habitabilidad para la vida señorial. En ellos, como decía Alfonso X el Sabio: las esposas que quieran dormir junto al señor estarán al lado del caballo ${ }^{26}$. Sólo servían para refugio de la tropa y de los campesinos en caso de ataque enemigo, pues el poblado se hallaba fuera de sus murallas. En La Rioja, además de los de Arnedo, Autol, Préjano, Arnedillo y Enciso, obedecen a esta tipología los de Cervera, Ocón, Jubera, Clavijo, Nájera, San Vicente de la Sonsierra, Davalillo en San Asensio, etc. ${ }^{27}$

A partir de los siglos XIII y XIV las construcciones defensivas, tal y como se habían concebido hasta ese momento, comienzan a decaer por el avance de la reconquista hacia el sur, que conlleva la desaparición de su función bélica, y surge otro tipo de arquitectura militar que se suele entregar por los reyes a particulares o a las órdenes militares como pago por algún servicio a la corona. Hasta el siglo XIV la nobleza no tenía castillos en propiedad, sino en tenencia no hereditaria, pero a partir de ahora, debido a estas donaciones o mercedes reales dadas a los nobles, aparecen castillos que deben su existencia no a la necesidad de defensa del territorio, sino al ascenso de dicha nobleza, y de ahí que se denominen castillos solariegos, señoriales, de señorío, nobiliarios, feudales, o palacios fortificados. Las antiguas tenencias pasan a

25. GUTIÉRREZ GONZÁLEZ, J. A, Op. cit., pp. 31-48.

26. VILLENA, L., "Sobre la evolución técnica del castillo español". Castillos de España, núm. 23, Segunda Época, Madrid, Asociación Española de Amigos de los Castillos, 1985, p. 58.

27. MOYA VAlGAÑón, J. G., RUIZ-NAVARRO PÉREZ, J., ARRÚE UGARTE, B., Castillos y Fortalezas de La Rioja. Logroño, Caja de Ahorros de La Rioja, 1992, pp. 55-57. 
propiedad y los castillos se adaptan para servir de residencia señorial de condes, marqueses y duques. En el siglo XV este fenómeno está ya muy generalizado, y su época álgida se da hasta el primer cuarto del XVI ${ }^{28}$. En la gegrafía riojana prolifera este tipo de fortaleza por la guerra civil que había tenido lugar en el siglo XIV entre el rey legítimo Pedro I el Cruel y su hermanastro Enrique II de Trastámara, apoyado por gran parte de la nobleza, y que finalmente le usurpó el trono.

Las características de este castillo vivienda son bien distintas a las del castillo defensa. Están construidos en piedra de sillería bien labrada, y como su función no es guerrera, sino de prestigio -aunque su actividad defensiva no falte-, son como palacios fortificados ubicados en Ilano en medio de las poblaciones. Su función es ahora gubernamental y de percepción de rentas, y militar sólo esporádicamente (levantamientos antiseñoriales, de señoríos rivales, de monarcas o de concejos, por ejemplo). Pretenden ser sobre todo un símbolo del poder del señor del lugar, que ejerce su dominio vasallático sobre los habitantes de las villas y aldeas próximas, y suele residir en él con su familia, o mediante sus representantes o administradores (alcaide, mayordomo). De ahí que estos castillos sean en realidad, más que lugares de protección y defensa, ostentosas residencias palaciegas de estos señores, dotadas de mejores, cómodas y lujosas estancias: torres del homenaje con hogares y cocinas, chimeneas, grandes salones palaciegos, servicios higiénicos o letrinas, capillas, balcones, ventanales con cortejadores, escaleras, escudos heráldicos y otros elementos ornamentales. Es la conversión de los castillos en palacios. Sin embargo, no dejan de introducirse nuevos elementos de tiro y defensa, como los matacanes o ladroneras, espolones, garitas, garitones, aspilleras, saeteras, troneras, puentes levadizos..., que en el siglo XVI se quedarán obsoletos por la generalización de la artillería. Las armas de fuego revolucionan la fortificación medieval pues convierten en inútiles los antiguos elementos de defensa y obligan a abandonar los viejos castillos o a construir otros utilizando nuevos elementos constructivos, o los mismos que antaño pero sólo con valor decorativo, para impresionar ${ }^{29}$. En nuestra región, los más importantes dentro de esta tipología son los de Cuzcurrita, Sajazarra, Leiva, Agoncillo, Quel y Cornago ${ }^{30}$.

A partir de los siglos XIV y XV también prolifera en ciertas zonas una tipología más sencilla llamada torre de vigilancia, de señales, óptica, vigía o atalaya, cuya función consiste, según indica su propio nombre, en vigilar los espacios que puede controlar visualmente, y en comunicarse con otras cercanas. Es ésta

28. VILLENA, L., Op. cit., p. 59. COOPER, E., Castillos Señoriales en la Corona de CastiIla. Vol. I. 1, Salamanca, Junta de Castilla y León, Ediciones Universidad de Salamanca, 1991, p. 29 y ss.

29. COOPER, E., Op. cit., pp. 65-66.

30. GUTIÉRREZ GONZÁlEZ, J. A., Op. cit., pp. 33, 41-43. MOYA VALGAÑóN, J. G., RUIZ-NAVARRO PÉREZ, J., ARRÚE UGARTE, B., Op. cit., pp. 60-61. 
la tipología en la que, según nuestro criterio, se incluiría el castillo de Herce. Son torres de carácter táctico, aisladas pero comunicadas entre sí, levantadas en lugares estratégicos, sobre cerros, desfiladeros y junto a pueblos, para alertar a los vecinos y vigilar cualquier movimiento de las tropas enemigas. Formaban un aparato de alerta que se ponía en funcionamiento cuando surgía algún peligro, mediante diversos métodos, como el de señales de humo o el de espejos. En esta red de torres, cada una se comunicaba con la más inmediata, y de ese rudimentario modo se podría tener controlada toda la zona; por ejemplo, en la España musulmana era posible enviar mensajes codificados por medio de señales de humo, desde el castillo soriano de Gormaz hasta Córdoba en unas cinco horas. Buscando su origen musulmán, Torres Balbás habla de un tipo de fortaleza o fortín Ilamado en árabe al-qusair y en romance alcocer, que se reduce a una torre con un espacio circundado por un muro al lado, de recinto reducido, parte baja maciza y, sobre ella, tres o cuatro pisos con suelos y techos de entramado de madera ${ }^{31}$. Los musulmanes Ilamaban al tipo de torre más primitivo qubba, y al-qubayba en diminutivo, denominación que pasó al castellano como alcoba o alcubilla, y al catalán como cubells ${ }^{32}$. Heras y Núñez les Ilama castillos con torre y recinto ${ }^{33}$. Por su simplicidad y sencillez, estas torres no solían tener elementos defensivos.

En la Rioja Baja responden a esta tipología, también de origen musulmán, las de Arnedillo, Préjano y Herce, y en la Rioja Alta las hay en la zona de la Obarenia, ubicada al noroeste de la región y regada por el río Tirón: Haro, Cellorigo, Villalba de Rioja, Tirgo y Foncea. Estas últimas, de cronología más tardía, pues la mayoría se datan en los siglos XIV y XV, se ubican en Ilano, en el centro de las aldeas (Haro, Cellorigo, Villalba de Rioja y Tirgo) o en pequeños riscos (Torre Mocha de Foncea). Sus muros son de sillería rellenos de morrillo, según el sistema constructivo de la época, y tienen un carácter más señorial que las de la Rioja Baja, quizás por lo avanzado de su cronología. Excepto la de Villalba que presenta planta trapezoidal, el resto la tienen rectangular o cuadrangular, un piso bajo y otros tres holladeros con forjados de madera y estrechas aspilleras, puerta de ingreso situada en uno de los pisos altos, como era costumbre, y coronamiento en terraza con matacanes corridos y almenas y escaraguaitas en los ángulos. La presencia de este otro tipo de arquitectura militar en la Baja Edad Media se debe a las terribles hambrunas y guerras que azotaron a las poblaciones durante el siglo XIV. De ahí que en estas zonas fronterizas expuestas a la inseguridad de esos tiempos se siguieran realizando construcciones defensivas y, no sólo

31. TORRES BALBÁS, L., Op. cit, pp. 153-154.

32. Esta sugerencia es recogida por la arquitecta encargada de la restauración del castillo de Herce en su proyecto: SOMER, G. M., Proyecto básico de restauración del castillo fuerte de Herce y la organización de su entorno. Préjano, mayo 2005. Inédito, quien se basa en Al Andaluz, The art of islamitic Spain. New York, The Metropolitan Museum of Art, 1992, pp. 65-66.

33. HERAS Y NÚÑ̃EZ, Maㅗ A. de las, Op. cit., p. 254. 
torres fuertes, sino casas fuertes señoriales, murallas y cortijos ${ }^{34}$. No obstante, la tipología de estas nuevas estructuras de defensa es distinta a las de la Alta Edad Media.

Junto a las fortalezas nobiliarias debieron coexistir las reales, caracterizadas por sus mayores dimensiones, destinadas a controlar las fronteras de Navarra y las grandes villas. De este tipo las hubo en Alfaro, Cervera, Calahorra, Logroño, Navarrete, Nájera, Briones o Bilibio (Haro), y precisamente muchas de ellas serán las primeras en desaparecer sin dejar rastro a lo largo de los siglos XVI y XVII, al perder su papel defensivo y ser sustituidas como control de tráfico y aduanero, por otro tipo de construcciones, a pesar de que algunas se reacondicionaron con fines señoriales. Sin embargo, los castillos señoriales perduraron más al quedar convertidos en eventuales residencias de la alta nobleza, desde donde ésta ejercía sus prerrogativas y practicaba la jurisdicción, y al ser, por tanto, centros de recepción de tributos, impuestos y de administración de rentas. Ahora bien, desde finales del siglo XVI, cuando Felipe II establece su corte definitivamente en Madrid, las familias nobles abandonan sus castillos en el campo para estar cerca del rey, y comienzan a quedar sin función. Posteriormente serán arrasados por las diferentes guerras que han azotado nuestro país (Guerra de Sucesión, Guerra de la Independencia, Guerras Carlistas, Guerra Civil...) y convertidos, a partir de la desaparición de los señoríos y mayorazgos en el siglo XIX, en símbolos de la tiranía del feudalismo, lo cual provocó que fueran despreciados, saqueados, destruidos y abandonados a su suerte ${ }^{35}$.

\section{El castillo de Herce}

\subsection{Datos geográficos}

La localidad de Herce, situada en la parte oriental de la región, forma parte de la Rioja Baja, del valle del Cidacos y de la subcomarca de Arnedo. Se ubica delante de los Montes de Bergasa y entre las Peñas de El Moro y El Salvador, ambas con restos de fortificaciones medievales, como veremos (Láms. 4-6). En la margen derecha del río se levanta la Peña Isasa, que domina todo el valle, y en la margen izquierda, al norte, esas paredes arcillosas de un rojizo tan característico, que casi no dejan espacio a los pueblos para desarrollar sus caseríos.

34. Los cortijos son pequeños recintos fortificados con función defensiva que servirían para protegerse de los ataques del enemigo en tiempos de inseguridad, y quizá para realizar en ellos otras actividades consuetudinarias en tiempos de paz. Uno de estos cortijos se descubrió adosado al norte de la iglesia parroquial de Tirgo al realizar unas excavaciones arquelógicas en 1997.

35. VILLENA, L., Op. cit., p. 63. MOYA VALGAÑÓN, José Gabriel, "Baja Edad Media. Los siglos del Gótico", en MOYA VALGAÑÓN, José Gabriel (dir.), Historia del Arte en La Rioja. II. Alta Edad Media, Románico y Gótico, Logroño, Fundación Caja Rioja, 2006, p. 264. 
Toda esta orilla izquierda del valle medio del Cidacos, desde Santa Eulalia Somera hasta Autol, presenta en esos cortados o farallones una serie de cuevas artificiales de gran valor histórico y etnográfico, que forman parte del peculiar paisaje de la zona.

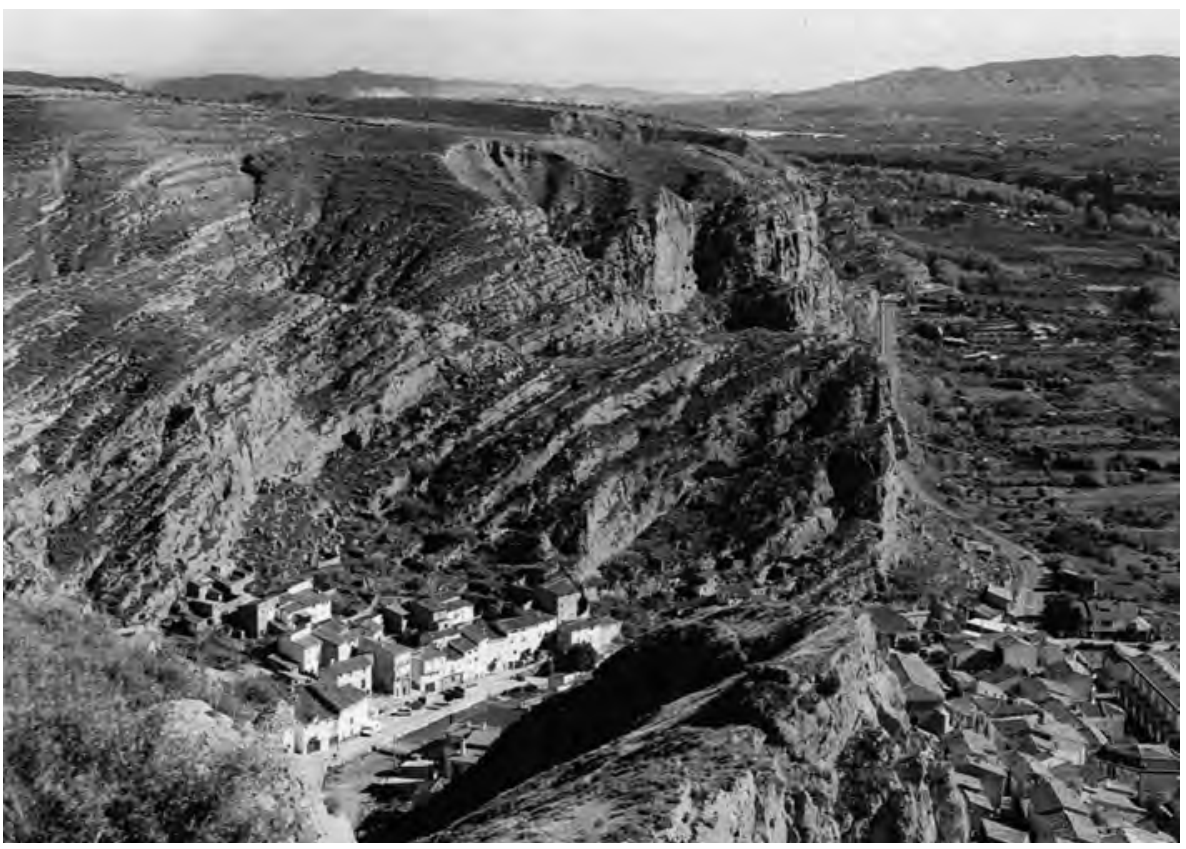

Lámina 4. Paisaje que se divisa desde el castillo de Herce hacia la zona oriental: caserío, Peña de El Moro, carretera hacia el valle bajo del Cidacos y Sierra de Yerga.

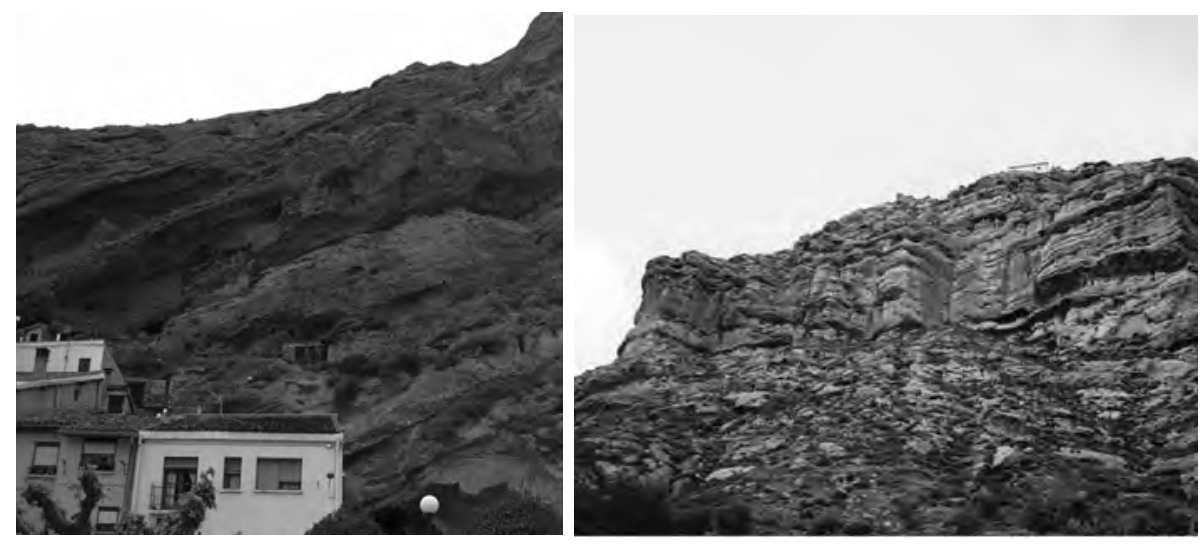

Láminas 5 y 6. Vistas de las Peñas de El Moro y El Salvador. 


\subsection{Datos históricos}

La villa de Herce se menciona en los privilegios o votos que el conde Fernán González dio a San Millán de la Cogolla para que el monasterio recibiera anualmente un censo en todas las poblaciones y regiones de su condado ${ }^{36}$. Respecto a este documento, es preciso aclarar que, aunque tradicionalmente se ha fechado en el año 93437, las últimas investigaciones apuntan a que sea una falsificación de finales del siglo XII o comienzos del XIII hecha por un monje Ilamado Fernando. Curiosamente, en la versión que publica Llorente de este documento sólo se cita Herce cuando lo traduce al castellano, omitiéndolo en la versión latina, junto con otros pueblos y lugares.

- Versión latina: ...Omnes villae de Ambobus Cameris, Urticosa, Enciso, Arnetiello, Ocone, Kelle, Abtolle, Bea, Calahorra... ${ }^{38}$.

- Versión castellana: ...Enciso, Arnedillo, Ocón, Peñaacha, Herce, Préjano, Arnedo, Kel, Autol, Bea, Calahorra.... ${ }^{39}$.

Los lugares omitidos en la versión latina, que en la castellana sí aparecen, son: Peñaacha (Peñalba), Herce, Préjano y Arnedo.

De los autores que publican el Cartulario de San Millán de la Cogolla, sólo Ubieto Arteta incluye el documento de los votos: ...Enciso, Arnetiello, Ocone cum suis villis, Penna Alva, Erze, Pressano, Kelle, Abtolle, Bea, Calahorra... ${ }^{40}$. Los pueblos o lugares citados son los mismos respecto a la traducción de Llorente, excepto Arnedo, que en esta versión no aparece.

Un tal Estéfano de Herce, que debía ser abad del monasterio de San Millán de la Cogolla, se menciona como testigo en el año 950 [o 956], cuando Adica y los monjes del monasterio del Monte Laturce se entregan a Dulquito, abad del monasterio de San Martín de Albelda, junto con la iglesia de San Vicente y la basílica de San Prudencio: ...Stefanus d'ercensis Sancti Emiliani abba ${ }^{41}$.

El 21 y el 30 de agosto de 1142 se cita una viña de un tal Domingo de Herce (vineam de Dominico dErz), con motivo del cambio que realiza Pedro, abad de

36. GOVANTES, A. C. de, Diccionario Geográfico-Histórico de España. Comprende La Rioja y algunos pueblos de Burgos. Sección II. Madrid, Real Academia de la Historia, Imprenta de los Sres. Viuda de Jordán e Hijos, 1846, p. 64.

37. LLORENTE, J. A., Noticias Históricas de las Tres Provincias Vascongadas. Vol. III, Madrid, Imprenta Real, 1807, doc. núm. 18, pp. 191 y ss., data los Votos de San Millán en el año 939.

38. LLORENTE, J. A., Op. cit., p. 196.

39. LLORENTE, J. A., Op. cit., p. 206.

40. UBIETO ARTETA, A., Cartulario de San Millán de la Cogolla (759-1076). "Textos medievales, 48", Valencia, Anúbar, 1976, doc. núm. 22, p. 38. SERRANO, L., Cartulario de San Millán de la Cogolla. Madrid, Centro de Estudios Históricos, 1930, no incluye el documento de los votos.

41. SAINZ RIPA, E., Colección Diplomática de las Colegiatas de Albelda y Logroño. (Tomo I: 924-1399). "Biblioteca de Temas Riojanos", Logroño, Diputación Provincial, IER, 1981, doc. núm. 3, pp. 3-4. 
Quel, con el obispo de Calahorra, Sancho, y su cabildo, de dos viñas del viñedo de Quel por una casa y heredad situada en Tarazona ${ }^{42}$.

Otros vecinos de Herce quedan reflejados en dos documentos de hacia 1152: Fernando Peláez, con su mujer Jimena, hija de Aznar Sanz de Herce, y su hijo Miguel Fernández, dona a Santa María de Calahorra antes de marchar en peregrinación al Santo Sepulcro -en tiempos del prior Juan Felices-, una serna que poseía en Préjano por donación de Alfonso VII y que Ilegaba hasta Herce; poco después su mujer Jimena y el presbítero de Herce Pascual, entregan los bienes en ella contenidos ${ }^{43}$.

Un tal Pedro López de Herce (Petrus Lupi de Erze) se cita en la donación que el 19 de abril de 1162 hizo Pedro Jiménez, señor de los Cameros, del término de Rute al monasterio de Sacramenia ${ }^{44}$.

En febrero de 1192, Mengo Gil, hijo de Herce, vende una viña al prior Juan de Préjano ${ }^{45}$. En septiembre de 1201, Lopeyón, hijo de Pedro Garcéiz de Herce, hace donación de sí mismo y de su hacienda a la iglesia catedral de Calahorra ${ }^{46}$. La villa se cita también en la escritura de asignación de rentas a la mesa capitular de la catedral de Calahorra, hecha por su obispo Juan de Préjano en $1200^{47}$.

En la Edad Media, Herce fue primero villa de señorío y después de abadengo. El el [9] u 11 de abril de 1173 había sido entregada en señorío por Alfonso VIII a Diego Jiménez de los Cameros y su mujer Guiomar Pérez de Traba por los servicios que aquél había prestado a la corona. Entre las posesiones de la villa, en este documento todavía no se cita ningún castillo: ..., uillam illam que uocatur Erce, in ualle de Arnedo sitam, totam ex integro, ui delicet, cum collaciis, terris, uineris, pratis, pascuis, riuis, molendinis, piscariis, montibus, fontibus, cum ingressibus et egre ssibus, ... ${ }^{48}$.

42. RODRÍGUEZ y RODRÍGUEZ DE LAMA, I., Colección Diplomática Medieval de La Rioja (923-1225). T. III: Documentos (1168-1225). "Biblioteca de Temas Riojanos", Logroño, Diputación Provincial, IER, 1979, doc. núm. 131, p. 210.

43. BUJANDA CIORDIA, F., "Archivo catedral de Calahorra". Berceo, núm. 77, Logroño, IER, 1965, p. 424. RODRÍGUEZ y RODRÍGUEZ DE LAMA, I., Op. cit., doc. núm. 167, p. 249, doc. núm. 168, p. 249.

44. RODRÍGUEZ y RODRÍGUEZ DE LAMA, I., Op. cit., doc. núm. 211 b, pp. 298-299.

45. BUJANDA CIORDIA, F., "Archivo catedral de Calahorra". Berceo, núm. 77, Logroño, IER, 1965, p. 438.

46. BUJANDA CIORDIA, F., Op. cit., p. 453.

47. HERGUETA y MARÍN, N., Colección de documentos para la historia de La Rioja. Vol. 3: años 1171 a 1285. Madrid, 1900. Archivo IER, M/228, doc. núm. 2 de 1200. MARTíN LOSA, F. (Director), y otros, Enciclopedia de La Rioja. Tomo 2. Logroño, Caja de Ahorros de Zaragoza, Aragón y Rioja, 1983, p. 88.

48. RODRÍGUEZ y RODRÍGUEZ DE LAMA, I., Colección Diplomática Medieval de La Rioja (923-1225). Tomo I: Estudio, Op. cit., p. 364. Idem, Colección Diplomática Medieval de La Rioja. Tomo III, Op. cit, doc. núm. 259, p. 34. 
Sin embargo en 1200, cuando Menga de Herce, hija de Mengo Álvaro de Herce, vende al prior de Calahorra, Pedro, tres viñas en Otura dentro del término de Herce, aparece citado un tal Miguel de Jubera como alcaide del castillo, siendo entonces señora de la villa Guiomar, pero ya viuda. De momento, es la primera cita documental encontrada sobre él, que demuestra su existencia a principios del siglo XIII: ... Dominante in Erz, domna Guiomar. Sub ea, alcaid in castello de Erz, don Michael de Iuuera. Merino, Domicu. Iudez, Mengo Michael. Saiona, Maria Boteiuda. Notum etiam sit omnibus hominibus quod domna Guiomar propter amorem prioris soltauit supradictam mediam honorem in pertuum in presentia domni Michaelis de luuera et domni Cornelii de Erz et Petri Aparicio de Arneto, sacerdotis, et Iohannis de Mengo Aluaro et aliorum multorum in castello de $\boldsymbol{E r Z}^{49}$. ("...Siendo señora de Herce, doña Guiomar. Bajo su autoridad, el alcalde del castillo de Herce, don Miguel de Jubera. ... en presencia de don Miguel de Jubera, de don Cornelio de Herce, del sacerdote Pedro Aparicio de Arnedo, de Juan Mengo Álvaro y de otros muchos en el castillo de Herce" ${ }^{\prime \prime}$.

Diego Jiménez fue, junto con sus hermanos Pedro y Teresa, el iniciador del linaje de los Cameros, aunque en esa época todavía no habían adquirido la titularidad del señorío. Su viuda, Guiomar, donó a la catedral de Calahorra en 1202, por el aniversario de su marido y de sus padres, dos sernas en Herce, la del Soto en la propia villa junto al río, y la de Fenoiares en Bergasa, lugar que dependía de Herce ${ }^{50}$. El 26-31 de diciembre del mismo año donó otras dos sernas en Herce y fue recibida por el cabildo de la catedral como hermana ${ }^{51}$. Estos documentos dejan entrever que a comienzos del siglo XIII Herce ya estaba organizado políticamente como concejo bajo la autoridad de la señora Guiomar.

María Álvarez de los Cameros, descendiente de estos y propietaria de la villa a mediados de la centuria, fundó junto con su esposo, Alfonso López de Haro, el 25 de noviembre de 1246, el monasterio de monjas bernardas, al que entregaron como dote las villas de Herce, Murillo de Calahorra, La Santa, Torremuña y Hornillos de Cameros ${ }^{52}$. A partir de entonces Herce tuvo jurisdicción de abadengo.

49. RODRÍGUEZ y RODRÍGUEZ DE LAMA, I., Colección... Tomo III, Op. cit., doc. núm. 396, pp. 173-174. Este documento se halla en el Archivo Catedral de Calahorra. (En adelante, ACC). Pergamino de 180x235 mm., sign. 159, y en el Libro de Arévalo, fol. 562, del mismo archivo.

50. RODRÍGUEZ y RODRÍGUEZ DE LAMA, I., Colección... Tomo I, Op. cit., p. 365. Idem, Colección... Tomo III, Op. cit., doc. núm. 405, p. 183.

51. BUJANDA CIORDIA, F., "Archivo catedral de Calahorra". Berceo, núm. 77, Logroño, IER, 1965, pp. 453-454. RODRÍGUEZ y RODRÍGUEZ DE LAMA, I., Colección... Tomo III, Op. cit., doc. núm. 411, p. 189.

52. Archivo Histórico Nacional. (En adelante, AHN), Clero, leg. 2.862, lib. 1, doc. núm. 5. 
En el Archivo Histórico Nacional hacen referencia a la fundación del monasterio varios documentos fechados el 25 de noviembre de $1246^{53}$, y en tres de ellos se citan las fortalezas que en ese momento existían en la villa, y que son donadas al cenobio:

- En uno de ellos se afirma que Alfonso López de Haro y su mujer, María Álvarez de los Cameros, donan la villa de Herce con sus dos castillos al monasterio de Santa María, situado en dicha villa, para que sus religiosas no tengan que mendigar:...Nos [quoque] in subsidium vite presentis ad opus iam dictarum abbatisse et monialium, in oprobium nostrum aliquo tempore mendicare cogantur, iam dicto mon[-aste-]rio supradictam villam Erz, et duo castra in ibi posita, (...) ut autem abbatissa et moniales prefatam villam et castra cum omnibus suis iuribus... ${ }^{54}$. ("...Nosotros también como subsidio de la vida presente, para la obra de las citadas religiosas y abadesa, y contra nuestra afrenta de otro tiempo, el verse obligadas a mendigar, desde ahora donamos al citado monasterio la antes mencionada villa de Herce y los dos castillos ubicados en ella, ... para que la abadesa y las religiosas [disfruten] de la nombrada villa y castillos con todos sus derechos...").

- En otro manuscrito, por el que los fundadores adscriben al Císter el monasterio y lo dotan con las villas de Herce, Murillo de Calahorra, La Santa, Torremuña y Hornillos de Cameros, se incluye en la donación de nuevo dichos castillos: ...Cui monasterio de Erz ego Aldefonsus Lupi de Faro et ego Maria Alvarez de los Camberos, uxor eiusdem Aldefonsi Lupi de Faro, damus per nos et per omnes successores nostros, libere et sine omni retentione, totam ipsam villam de Erz cum castris ibidem constructis et cum omnibus iuribus pertinen[-ti-]bus ad eandem;... ${ }^{55}$. (“...A este monasterio de Herce yo, Alfonso López de Haro, y yo, María

53. AHN, Clero, leg. 2.862, lib. 1, docs. núm. 4, 5, 6 y 7.

54. Este documento se encuentra en el Archivo del Real Monasterio de la Anunciación de Religiosas Bernardas de Santo Domingo de la Calzada (en adelante, SANTO DOMINGO), y en el Archivo Histórico Nacional, el cual es una copia de finales del siglo XVIII. SANTO DOMINGO, Sección Herce, Perg. 190 × 166 mm. Roto y con faltas de pergamino que afectan al texto. AHN, Sección Clero, leg. 2.862, lib. 1, doc. núm. 32.

Lo recoge en su Tesis Doctoral, PÉREZ CARAZO, P., Santa María de Herce y su abadengo en la Edad Media. Logroño, Instituto de Estudios Riojanos, Universidad de La Rioja, 2008, obra que contiene el capítulo "10. Documentación", en CDRom: La Colección diplomática medieval de Santa María de Herce y su abadengo en la Edad Media. Doc. núm. 9, p. 52.

55. SANTO DOMINGO, Sección Herce, Perg. 440 × 240 mm. Perg. $675 \times 545$ mm. Privilegio rodado del rey Alfonso X el Sabio, dado en Logroño a 10 de febrero de 1270, en el que incluye traslado literal de este documento y lo confirma. AHN, Sección Clero, leg. 2.862, lib. 1, doc. núm. 5.

PÉREZ CARAZO, P., Op. cit., doc. núm. 12, pp. 59. 60. RODRÍGUEZ y RODRÍGUEZ DE LAMA, I., Colección... Tomo I, Op. cit., p. 367. 
Álvarez de los Cameros, esposa del mismo Alfonso López de Haro, damos en nuestro nombre y en el de todos nuestros sucesores libremente y sin retención alguna, toda la mismísima villa de Herce con los castillos allí mismo construidos y con todos los derechos que le corresponden, ...").

- En otro de los documentos de fundación de 1246, idéntico al anterior a excepción de que en él que se indican las mugas de los términos de alguna de las villas adheridas al monasterio, se vuelven a citar las fortalezas: ...Cui monasterio de Erce et ego Alfonsus Lupi de Faro et ego Maria Alvarez de los Camberos, uxor eiusdem Alfonsy de Faro, damus per nos et per omnes successores nostros, libere, sine omni retentione, totam ipsam villam de Erce cum castris ibidem constructis et cum terminis, scilicet:....56. ("...A este monasterio de Herce yo, Alfonso López de Haro, y yo, María Álvarez de los Cameros, esposa del mismo Alfonso López de Haro, damos en nuestro nombre y en el de todos nuestros sucesores libremente y sin retención alguna, toda la mismísima villa de Herce con los castillos allí mismo construidos y con los términos, a saber,...").

Hasta el siglo XV no volvemos a encontrar menciones de nuestro interés, relativas a la villa de Herce. El 15 de diciembre de 1439 Gil Martínez de Herce vende a Gil Ruiz una parte de Salzar ${ }^{57}$. El 29 de marzo de 1455 los préstamos de Herce y Préjano que antes eran de la Dignidad de Tesorero de Calahorra, ahora se adjudican a la fábrica directamente ${ }^{58}$. El 2 de mayo de 1468 el notario Martín Martínez da testimonio en Yanguas de cómo Juan Ramírez de AreIlano y su mujer Isabel Enríquez, señores de Cameros, fundaron en la capilla de los Mártires de la catedral de Calahorra dos capellanías y tres misas perpe-

56. SANTO DOMINGO, Sección Herce, Perg. 560 × 230 mm. aprox. Muy roto y borroso, con grandes faltas de pergamino que hacen ilegible la mayor parte del texto. Perg. $512 \times 210$ $\mathrm{mm}$. aprox. Muy roto y borroso, con grandes faltas de pergamino que hacen ilegible la mayor parte del texto.

AHN, Sección Clero, leg. 2.862, lib. 1, doc. núm. 7. Lib. 5.760, doc. 238, 1 hoja de papel de $435 \times 310 \mathrm{~mm}$. Traslado notarialmente compulsado en Herce por el notario públio de la villa Fernán Jiménez de Préjano el 5 de diciembre de 1480. Lib. 5.760, doc. 542.1 hoja de papel suelto, sin foliar. Traslado notarialmente compulsado por Francisco Ramírez, el 5 de mayo de 1721. Lib. 5.763, fols. 211-214. Traslado notarialmente compulsado en 1724. Lib. 5.750, doc. 237. Traslado notarialmente compulsado en Herce por Nicolás de Ascarza Eguía, a 18 de enero de 1746.

PÉREZ CARAZO, P., Op. cit., doc. núm. 13, pp. 63, 64. REINARES MARTíNEZ, E., Documentación referente al monasterio de religiosas bernardas de Santa María la Real en la villa de Herce y de su señorío abacial sobre las villas de Herce, Hornillos, La Santa y Torremuña. Trabajo inédito. Madrid, 1983. IER, pp. 1-3.

57. BUJANDA CIORDIA, F., "Archivo catedral de Calahorra". Berceo, núm. 78, Logroño, IER, 1968, p. 70.

58. BUJANDA CIORDIA, F., Op. cit., p. 73. 
tuas, dotándolas con un juro de 10.000 maravedís en la villa de Herce: ...diez mill marauedis de iuro de heredat que tienen por preuillegio situados en las alcaualas del lugar de Herçe que es del monesterio de Sancta Maria de Herçe... ${ }^{59}$. Este privilegio de juro de heredades sobre las rentas de las alcabalas de Herce en favor de la catedral y cabildo de Calahorra, dado por el rey Enrique IV, es confirmado por la reina Juana en 1509, previa renuncia a él por parte del arzobispo de Toledo y antes de Pedro de Luján, para fundar dos capellanías en la capilla de los Mártires de la catedral de Calahorra, donde estaba enterrada Isabel Enríquez, mujer del señor de los Cameros Juan Ramírez de Arellano: ...los dichos diez mill marauedis en las alaualas de Erçe ${ }^{60}$. El 28 de julio de 1488 el papa Inocencio VIII concede en Roma una bula por la que incorpora a la fábrica de la catedral de Calahorra los préstamos de Herce y Préjano, que anteriormente eran de la Tesorería ${ }^{61}$.

En el Registro General del Sello del Archivo General de Simancas se conservan documentos relativos a Herce de un periodo de tiempo muy concreto dentro de fines del siglo XV y comienzos del XVI. De ellos nos interesa especialmente el que menciona una fortaleza que se estaba construyendo en la villa: el 24 de julio de 1494, los Reyes Católicos a través del Consejo de Castilla y León, dictan una comisión desde Segovia al corregidor de Calahorra y Logroño, el licenciado Francisco de Vargas, a petición del monasterio de Santa María de Herce, sobre los atropellos que les estaba causando Juan de Berrañón, vecino de Arnedo, el cual se había construido una fortaleza cerca de la villa de Herce, que pertenecía a dicho monasterio ${ }^{62}$.

Los Reyes Católicos se dirigen a Francisco de Vargas diciéndole que la abadesa y monjas del monasterio de Herce les habían informado de que ...Juan de Berraño, vezino de la villa de Arnedo, diz que les ha fecho e faze muchas tomas e fuerças, asý en los bienes e rentas del dicho monasterio como a sus

59. BUJANDA CIORDIA, F., Op. cit., pp. 74, 75. SAINZ RIPA, E., ORTEGA LÓPEZ, A., Documentación calagurritana del siglo XV. Archivo catedral. "Biblioteca de Temas Riojanos", Logroño, IER, Gobierno de La Rioja, 2004, doc. núm. 79, p. 287.

60. SAINZ RIPA, E., ORTEGA LÓPEZ, A., Op. cit., doc. núm. 73, pp. 250-260, mención de Herce en p. 254. Este documento está confirmado en varias fechas: 16 y 18 de mayo y 5 de junio de 1465, 18 de diciembre de 1472, y 21 de junio y 17 de julio de 1509 .

61. BUJANDA CIORDIA, F., Op. cit., p. 137.

62. Archivo General de Simancas. Registro General del Sello. (En adelante, AGS.RGS). Doc. núm. 2.491, fol. 185. Publicado en Archivo General de Simancas. Registro General del Sello. Vol. XI (Enero-diciembre 1494). Madrid-Valladolid, CSIC, Biblioteca "Reyes Católicos", Instituto Jerónimo Zurita, 1970, p. 383.

AGS.RGS. Doc. núm. 2.492, fol. 186. Publicado en Archivo General de Simancas. Registro General del Sello. Ibidem). Lo publican también COOPER, E., Castillos Señoriales... Vol. II, Apéndice documental, Op. cit., doc. núm. 208, pp. 1055-1056, y PÉREZ CARAZO, P., Op. cit., doc. núm. 270, pp. 805-806, y doc. núm. 271, pp. 807-808. 
vasallos,..., y que como está muy favorecido por el señorío de la villa de Arnedo, sugieren que una buena persona como el corregidor citado haga justicia por ...todas las fuerças e daños e sinrazones quel dicho Juan de Berraño les oviese fecho e fiziese de aquí adelante... ${ }^{63}$. En principio no se especifican los daños causados, pero a continuación se alude a que Francisco de Vargas debe informarse sobre la fortaleza que Juan de Berrañón se está construyendo cerca de la villa de Herce, pues la abadesa sostiene que le perjudica mucho, y que como no tiene permiso suyo para edificarla, debe derribarse: ... Sepades que por parte del abadesa e monjas e convento del monesteryo de Santa María d'Arze nos fue fecha relaçión por su petición, que ante nos en el nuestro Consejo fue presentada, diziendo que un Juan de Berraño, vesino de la villa de Arnedo, non lo podyendo nin deviendo hazer asý por estar defendido por las leys de nuestros reynos commo por non tener liçencia para ello de nos, dis que faze e edifica çerca de la villa de Arze, que es del dicho monasterio, de la qual espera sy se acabase se recreçería mucho daño e perjuizio a la dicha villa e vezinos e moradores della e de la comarca, porque los fatygaría e haría muchos agravios; e que pues a nos, commo rey e reyna, en lo tal pertenesçie prover e remedyar mandásemos dar nuestra carta para que la obra de dicha fortaleza çesase e lo que está fecho se derrivase, (...) veyades el logar donde el dicho Juan de Berraño haze e edifica la dicha fortaleza e veáys por vista de ojos la dicha fortaleza que asý el dicho Juan de Berraño haze e, sy non tyene de nos la dicha liçencia para la hazer, que agáys que çese la obra della, e demandéys de nuestra parte a dicho Juan de Berraño e a otras cualesquier personas que non labren ni edifiquen más en ella, hasta tanto que presente ante nos la liçencia e týtulos que para hazer tyene, (...) que es el daño e perjuizio que resçebiría al dicha villa de Arze e las otras villas e logares de la comarca, sy la dicha fortaleza sy hiziese; e por qué týtulo e razón el dicho Juan de Berraño haze la dicha fortaleza; e la pesquisa fecha e la verdad sabida, y con la relaçión de la dicha fortaleza, la enbiad ante nos al nuestro Consejo,... ${ }^{64}$.

Desgraciadamente, en ningún momento se precisa el lugar donde se estaba construyendo dicha fortaleza, y tampoco se sabe cómo acabó el asunto: si finalmente Juan de Berrañón pudo terminarla o si tuvo que derribar lo que había edificado.

Según se refleja en otros documentos de Simancas, Carlos de Arellano, conde de Aguilar y primo de la entonces abadesa de Herce, compraba solares

63. AGS.RGS. Doc. núm. 2.491, fol. 185. PÉREZ CARAZO, P., Op. cit., doc. núm. 270, p. 805.

64. AGS.RGS. Doc. núm. 2.492, fol. 186. PÉREZ CARAZO, P., Op. cit., doc. núm. 271, pp. 807-808. 
en la villa poco después, entre 1504 y 1506, y construía un castillo para perpetuar la encomienda establecida por su abuelo. No está claro si la fortaleza de Juan de Berrañón formaba parte de este castillo o no. En marzo de 1506 el citado Carlos de Arellano y su primo, Juan de Arellano, señor de Ausejo, ocuparon Herce con cincuenta y cinco hombres de a caballo y setecientos u ochocientos peones. El día 25, estando la Corona en Valladolid, ordenó a Alonso de Torres y Juan de Ribera, capitán general de la frontera de Navarra, que averiguaran lo sucedido y suspendieran las obras del castillo65. En enero de 1507, el conde volvió a ocupar Herce con dos mil hombres de armas, según se deduce de una orden dada por la Corona en Burgos el 14 de diciembre de ese año al bachiller Lobera para que investigara la situación ${ }^{66}$. No obstante, según indica Cooper, había otros muchos interesados en estos momentos en ocupar Herce, como Alonso de Arellano, hermano de la abadesa y señor de Clavijo, sus hermanos Fadrique de Arellano y Juan Ramírez de Arellano, así como el conde de Nieva, el duque de Nájera y Pedro de Luna, este último señor de Cornago $^{67}$. El 23 de noviembre de 1506 la reina Juana había escrito al concejo de Herce para ordenar que no vendiera ni casas ni heredades a Fadrique de Arellano y días después, el 15 de diciembre, ordenó a éste que no comprara nada en la villa porque la abadesa y el convento desconfiaban y tenían varios pleitos con él68.

$\mathrm{Y}$ a partir de este momento, inevitablemente tenemos que dar un salto hasta el siglo XX, pues el silencio documental es absoluto. Tampoco a simple vista hay evidencias materiales o arqueológicas de intervenciones posteriores en el castillo conservado hoy en el Cerro de El Salvador, excepto la construcción de la propia ermita homónima. La situación actual de las ruinas es curiosa, pues siendo de propiedad municipal, están enclavadas en una finca privada de suelo rústico. En documentos de 1930 aparece la ermita como uno de los bienes inmuebles del Ayuntamiento de Herce, que linda por los cuatro lados con un te-

65. AGS.RGS. Marzo de 1506, sin foliar. Publicado por COOPER, E., Op. cit., p. 1.056. La búsqueda de este documento en el Archivo General de Simancas, basada en la citada alusión de Cooper, ha resultado infructuosa. Existe otro manuscrito de contenido similar, protagonizado por las mismas personas, fechado en Valladolid el 27 de marzo de 1506, fol. 147, que trata de una comisión, a petición de Juan de Arellano, dada a Juan de Ribera y al bachiller Torres, pero se refiere a la villa de Ausejo, y no alude a Herce ni a su fortaleza. La poca precisión de Cooper a la hora de citar este manuscrito, probablemente debida a que entonces no se hallaba paginado, dificulta considerablemente su hallazgo.

66. AGS.RGS. Diciembre de 1507, sin foliar. Publicado por COOPER, E., Op. cit., p. 1.056. En este caso sí ha sido encontrado el documento, pero tampoco en él se dice nada del castillo de Herce. Agradezco el envío de ambos a Francisco Javier Álvarez Pinedo, Subdirector del citado archivo.

67. COOPER, E., Ibidem

68. HERGUETA y MARÍN, N., Colección de documentos para la historia de La Rioja. Vol. 4. Madrid, 1900. Archivo IER, M/229, docs. núm. 2 y 3 de 1506. 
rreno particular de Dolores Sesma ${ }^{69}$. Esta finca, Ilamada también de El Salvador, ocupa prácticamente todo el cerro y, por tanto, incluye el castillo y es la que en 1964 el Ayuntamiento intentó adquirir, aunque sin éxito, siendo entonces propiedad de las Señoras Ugarte Sesma ${ }^{70}$.

$* * * * * * *$

Como acabamos de comprobar, son muy escasos los datos históricos existentes sobre los castillos, fortalezas o torres de defensa que hubo en Herce, pues apenas se mencionan en las fuentes. Lo que sí parece claro es que éstas nos hablan de distintas construcciones. En el siglo XIII existían dos que controlarían el pasillo natural hacia Soria, hoy conocido como camino de Bergasillas, facilitado en su día por la yasa de Fuente Vieja -ramal derecho de la yasa de Valeros-, la cual discurre entre los dos cerros que dominan el pueblo, el de El Moro y el de El Salvador, cuyas paredes verticales contienen multitud de cuevas con nichos, principalmente, las orientadas hacia el sur. Estos dos castillos, situados probablemente sobre dichos cerros, controlarían este antiguo paso hacia Soria entre los valles de Ocón y Ebro y la antigua vía romana del Cidacos que cruzaba hacia Préjano junto al asentamiento de Las Losas ${ }^{71}$.

Ahora bien, en ninguna de las primeras citas (fechadas en 1200 y 1246) se comenta dónde estaban exactamente, si bien puede deducirse que probablemente uno de las dos nombrados en 1246 se corresponda con los restos de la torre de El Salvador. El de la Peña de El Moro no se conserva como tal, pero es fácil deducir que quizá fuera una fortaleza de carácter rupestre como las que hubo en los valles del Iregua (Viguera, Castañares de las Cuevas e Islallana), y Alhama (Cervera e Inestrillas), ya que en su vertiente meridional quedan restos de carácter defensivo en la propia roca: muretes que pudieron estar relacionados con las cuevas e improntas de vigas de madera que quizá sirvieron para construir cadalsos.

69. Archivo Histórico Provincial de La Rioja. (En adelante AHPLR). Documentación de Hacienda. Herce. 1930. Cuadernillos de comprobación catastral. Sign. HA/9.268. Herce. 1930. Expedientes de comprobación catastral. Sign. HA 221/224, HA 224/229.

Archivo Municipal de Herce. (En adelante AMH). Patrimonio. Expedientes de bienes. Certificado, que presenta el secretario, de las fincas propiedad del Ayuntamiento para su inscripción en el Registro de la Propiedad. 1930. Sign. 042/19.

70. AMH. Patrimonio. Expedientes de bienes. Expediente de autorización para la adquisición de la finca El Salvador. 1964. Sign. 043/09.

71. PASCUAL MAYORAL, P., PASCUAL GONZÁLEZ, H., Carta arqueológica de La Rioja. I. El Cidacos. Logroño, Col. "Amigos de la Historia de Calahorra", 1984, p. 69. PASCUAL MAYORAL, P., "Columbarios de La Rioja y su distribución geográfica", en GONZÁLEZ BLANCO, A. (Editor), Los columbarios de La Rioja. Antigüedad y cristianismo, núm. XVI, Murcia, Universidad de Murcia, Área de Historia Antigua, 1999, p. 111. En esta obra se cita el cerro de San Bartolomé como uno de los que tuvieron castillo, pero pienso que debe ser un error pues según los vecinos de Herce, allí no existe ningún cerro con tal nombre. 
En cuanto a restos arquitectónicos propiamente dichos, aparte de las ruinas del castillo de El Salvador, que analizaremos a continuación, y de los vestigios citados en la Peña de El Moro, quedan restos de dos más en los topónimos de El Castillar y El Cueto, incluidos en los dos cerros principales ${ }^{72}$. En El Castillar, situado encima y a la izquierda de la yasa de Valeros, dentro del cerro de El Salvador, pero a un nivel más bajo que su cumbre, subsisten restos de fortificaciones construidas con encofrado de tierra apisonada, tapial y sillarejo, técnica similar a la utilizada en el castillo de Enciso, existiendo también sillares y mampuestos $^{73}$ (Lám. 7), así como escaleras rupestres de acceso desde el propio barranco, y otras huellas de canalizaciones realizadas en la roca para desviar el agua entre la multitud de cuevas-bodega existentes en la zona, el Ilamado Barrio de los Buenos (Lám. 8). En El Cueto, paraje ubicado a la derecha de la yasa de Valeros en lo más alto de la Peña de El Moro, cuajada también de multitud de cuevas con funciones diversas (bodegas, leñeras, pajares...), a las que se accede mediante más escaleras talladas en la roca (Lám. 9), hay restos de canalizaciones de agua que quizá alimentaran algún aljibe y gruesos muros de sillería con relleno de morrillo, como los de El Salvador ${ }^{74}$ (Lám. 10). Probablemente son vestigios de otra fortificación medieval, aunque muy remodelada posteriormente, pues en uno de los vértices se aprecian restos modernos de ladrillo y yeso, quizá producto de una reutilización del conjunto como corral. Todo esto nos sugiere que Herce contaba en la Edad Media con un sistema defensivo compuesto de dos castros principales ubicados en los dos cerros, del que nos han llegado restos de diversa índole y consideración: por un lado, en El Salvador, una torre de sillería rellena de morrillo con su muralla defensiva, y un poco más abajo, en El CastiIlar -topónimo que habla por sí solo-, fragmentos de una construcción de tapial y sillarejo; por otro lado, en Peñalmoro, improntas y restos de muretes en la roca, y en su zona más elevada, El Cueto -topónimo también bastante clarificador-, restos de otro edificio de sillería y morrillo.

Respecto a la propiedad de los castillos de Herce citados en las fuentes, el existente en 1200, cuyo alcaide era Miguel de Jubera, pertenecía a Guiomar, señora de la villa y viuda del señor de Cameros Diego Jiménez. Los dos castillos mencionados en 1246 eran en principio también de los señores de Cameros, pero estos los donaron al monasterio cisterciense que fundaron, integrándose en el patrimonio monástico desde el principio. Por tanto, y a menos en teoría, pasarían de manos laicas (señores de Cameros) a religiosas (abadesa), al igual que la propia villa y que el resto de propiedades y bienes donados. Ahora bien, no es descabellado pensar que en la práctica siguieran

72. Desde aquí agradezco a Pedro Pérez Carazo el haberme acompañado a visitar los restos de estas fortificaciones en marzo del año 2006.

73. PÉREZ CARAZO, P., Santa María de Herce y su abadengo en la Edad Media. Logroño, Instituto de Estudios Riojanos, Universidad de La Rioja, 2008, pp. 81-83.

74. PÉREZ CARAZO, P., Op. cit., pp. 81, 84-85. 
siendo ellos, como patronos del monasterio, los que ejercieran un control directo sobre estas fortificaciones. En el manuscrito del siglo XV (1494) sí se especifica claramente que la fortaleza que se pretendía construir en ese momento era de un vecino de Arnedo llamado Juan de Berrañón, pero tampoco se aclara su ubicación ni si formaba parte de otro castillo que a comienzos del siglo XVI (1504-1506) construía el conde de Aguilar Carlos de Arellano, cuyas obras la Corona también ordenó suspender.
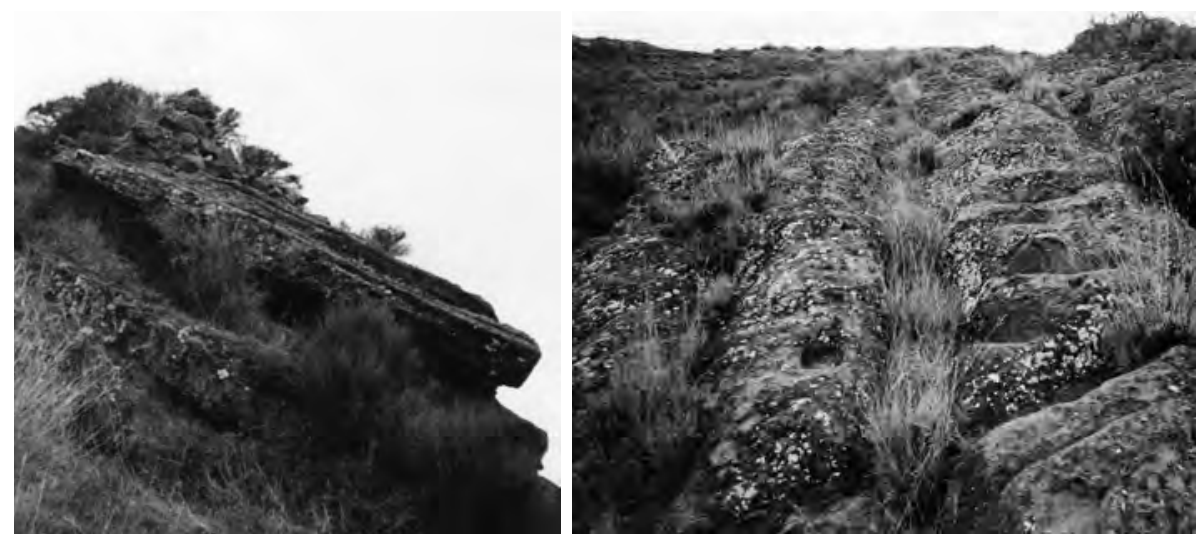

Láminas 7 y 8. Restos de construcción de tapial y sillarejo en El Castillar y canalizaciones realizadas en la roca en la zona de acceso a dicho lugar.
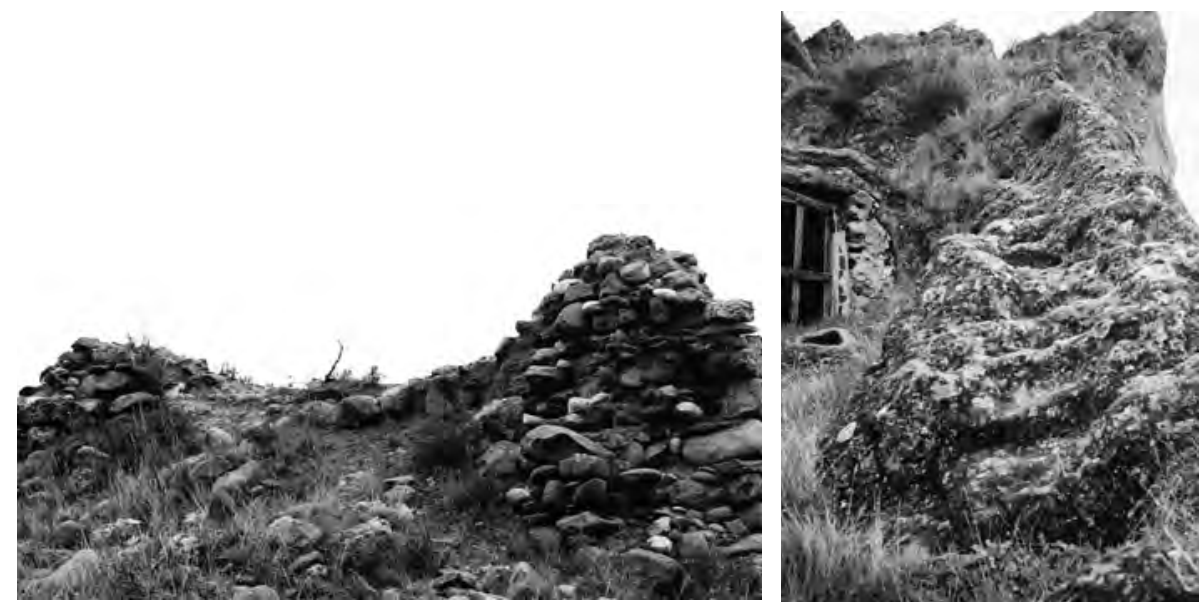

Láminas 9 y 10. Restos de construcción de sillería rellena de morrillo en El Cueto y escaleras talladas en la roca en la subida o dicho lugar. 
Después de la reconquista los demás castillos del valle del Cidacos pertenecieron a los señores del lugar, fueran nobles, eclesiásticos o reyes: el de ArnediIlo fue de los obispos de Calahorra; el de Arnedo de los señores de la villa -los Fortuniones primero y los Fernández de Velasco después-; el de Quel, del señor de la villa García Sánchez de Alfaro el Viejo; y los de Autol y Calahorra, de los monarcas de turno. Quizá los de Yanguas, Enciso y Préjano sean los que más se puedan relacionar con el de Herce, ya que en determinados momentos de su historia, todos ellos fueron propiedad de los señores de Cameros. Estos tres pertenecieron también a la orden de Calatrava, pues fueron vendidos por aquéllos a la misma en 1284, pero no podemos saber fehacientemente si el de Herce tuvo algo que ver en con ella, aunque pensamos que no, ya que la documentación no apunta nada en ese sentido. También fue de dicha orden, aunque desde 1459, el castillo de Briones $^{75}$.

\subsection{Cronología, tipología y descripción de los restos conservados}

Dada la escasez de fuentes documentales, la datación de los únicos restos de construcción defensiva de cierta entidad que han subsistido al paso del tiempo en la localidad de Herce, debe hacerse teniendo en cuenta únicamente sus materiales, técnica constructiva y formas arquitectónicas. De este modo, por el aparejo de sus muros y por el uso de bóvedas de cañón apuntado y de crucería, su cronología no puede retrotraerse más allá del siglo XIII, que casualmente es cuando se empieza a mencionar en los textos escritos. Ahora bien, eso no quiere decir que no existiera otro castillo en la zona con anterioridad. De hecho, en las excavaciones arqueológicas efectuadas por David Eguizábal aparecieron, junto a restos de vasijas medievales del siglo XIII, otros fragmentos cerámicos, posiblemente islámicos del siglo VIII.

Es difícil establecer la cronología de un castillo por varias razones ${ }^{76}$ :

- No se suelen encontrar fácilmente en la documentación citas relacionadas con la construcción de este tipo de edificios. A lo sumo, puede aparecer una alusión que acredita su existencia en un momento determinado,

75. El 20 de octubre de 1459, Enrique IV cedió el señorío de la villa de Briones a Pedro Girón, maestre de la orden de Calatrava. Ver al respecto, CANTERA MONTENEGRO, E., "El castillo de Briones (La Rioja) a mediados del siglo XV". Estudios Mirandeses / 2. Miranda de Ebro, Fundación Cultural "Profesor Cantera Burgos", 1982, pp. 85-104, quien cita a SOLANO, E., La Orden de Calatrava en el siglo XV. Los señoríos castellanos de la Orden al fin de la Edad Media. Universidad de Sevilla, 1978, porque en esta obra se estudian otros castillos que pertenecieron a dicha orden como los de Huerta de Valdecarábanos, Zorita de los Canes, Manzanares, Porcuna o Peña de Martos.

76. HERAS y NÚÑ̃EZ, Ma A. de las, Estructuras arquitectónicas riojanas. Siglos X al XIII. "Biblioteca de Temas Riojanos", Logroño, IER, Gobierno de La Rioja, 1986, p. 49. 
sin más. Por ejemplo, en nuestro caso, sabemos que en Herce existía una fortaleza en 1200, otras dos en 1246 y otras más en construcción en 1494 y 1506. Si la primera mención documental se refiere a la que que venimos estudiando, probablemente sería una construcción anterior a la que ha llegado a nuestros días.

- Las estructuras, sistemas constructivos, formas arquitectónicas y tipo de aparejos utilizados permanecieron muchos siglos sin alterarse, lo cual nos impide ofrecer una datación precisa si sólo tenemos en cuenta las ruinas arquitectónicas que se han conservado. Las formas de los arcos empleadas en los vanos (herradura, medio punto, apuntado, rebajado, mitrado, lobulado...) y los tipos de bóvedas (medio cañón, arista, crucería...) son un buen indicador cronológico. Pero no siempre las formas de aspecto más rudo o arcaico son las más antiguas, pues pueden ser imitaciones retardatarias de prototipos anteriores. Sin embargo, en nuestro castillo, el arranque de las bóvedas es el único elemento constructivo que tenemos para datarlo.

- La desaparición en la mayoría de los casos de la decoración monumental de estas construcciones también nos impide fecharlas con exactitud, pues los motivos ornamentales son indicadores bastante importantes de una época determinada. Ahora bien, pierden todo su valor en este sentido cuando se utilizan de una forma arcaica durante varios siglos. En Herce no podemos utilizar este indicador cronológico pues las ruinas de la torre no poseen ningún elemento de este tipo.

- Las transformaciones que sus formas arquitectónicas han sufrido con el paso del tiempo (reconstrucciones sucesivas, restauraciones excesivas y poco rigurosas, destrucciones por guerras o catástrofes naturales, abandono, etc.) también falsean el aspecto real del castillo y dificultan su cronología. De ahí que en muchas ocasiones las formas de los vanos o el remate almenado sean producto de la fantasía restauradora. En nuestro caso, como el conjunto ha sido restaurado por primera vez, afortunadamente no hemos tenido que desechar ningún elemento añadido con posterioridad.

La ubicación del castillo de Herce junto a la ermita de El Salvador en un escarpe rocoso de la peña del mismo nombre, que domina el valle del Cidacos al noroeste del pueblo, obliga a que el acceso con vehículos se realice por la vertiente norte a través de un sinuoso y empinado camino rural sin asfaltar de reciente construcción (Fig. 1). No obstante, por el lado oriental existe otro sendero peatonal entre las peñas que se usa para subir en mayo a la ermita en romería. Dentro del conjunto monumental integrado por el castillo y la ermita, aquél se sitúa al noroeste de ésta. Su situación exacta es, según el Mapa Topográfico Nacional: S.G.E. E: 1/50.000. Hoja: 24-11 (243). Coordenadas U.T.M.: X.:568.500/ 
Y.:4.674.20077. La superficie aproximada del conjunto es de $430 \mathrm{~m}^{2}$, y la del propio castillo, de 116,4 $\mathrm{m}^{2} 78$.

En realidad, más que un castillo era una atalaya o torre fuerte, hoy completamente desmochada, pues sólo quedan retazos de tres muros, el norte completo y la mitad del este y del oeste, y ninguno de ellos conserva la altura que originalmente tuvieron. La otra mitad de dicha torre, es decir, todo el muro sur, que se orienta hacia el precipicio y hacia el valle, y el resto de los muros oriental y occidental desaparecieron en un desplome de la roca del monte sobre la que se asienta (Figs. 2 y 3, Láms. 11 y 12). Suponemos que parte de la pérdida de material se debe también a su reciclaje y reaprovechamiento en otras construcciones de la zona, quizás en la propia ermita.

Es uno de los prototipos de castillo roquero o roqueño y, probablemente, no fue construido ex novo en el siglo XIII, sino que tuvo que sustituir a otro anterior edificado en la Alta Edad Media, relacionado quizá con las luchas de conquista y reconquista entre musulmanes y cristianos, el cual, probablemente, se arruinó pronto. Por su estratégica situación, dominando un amplio campo visual del valle medio del Cidacos, pudo ejercer como torre de vigilancia, de señales, óptica, vigía o atalaya para vigilar los amplios espacios que controla visualmente, y para comunicarse con los otros castillos o torres de la zona (Lám. 4). De este modo, el valle del Ebro hacia Soria pudo haber estado comunicado por una línea de fortificaciones a lo largo del Cidacos, que en algunos casos eran torres aisladas y en otros auténticos castillos: Calahorra, Autol, Quel, Arnedo, Herce, Préjano, Arnedillo, Enciso, Yanguas... Somer apunta incluso la falta de otro hipotético castillo o torre en el Monte Castellar, en la curva del río entre Santa Eulalia y Arnedillo ${ }^{79}$.

La torre de Herce era de planta cuadrangular con ingreso hacia el este, pero las ruinas que quedan tienen forma de L. Los muros, muy espesos y macizos, de gran grosor y calidad, eran de aparejo de sillarejo y sillería de arenisca de la zona rellena con morrillo. A pesar del deterioro, se aprecia que, en general, la vertiente interna se realizó con sillares bien escuadrados (Lám. 13), mientras que la externa es de sillarejo (Láms. 11 y 12). El norte mide 4,50 m de grosor, el este, 5,15 m y el oeste, 1,80 m (Fig. 2). Todos ellos están desmochados en su parte superior, así como llenos de cascotes y muy descarnados, sobre todo, la zona más occidental del muro norte (Fig. 3, Láms. 14, 15). Las alturas de estos muros oscilan entre los casi $7 \mathrm{~m}$. (6,93 m) del exterior del muro oeste, hasta hasta el metro y medio $(1,55 \mathrm{~m})$ del exterior del muro este.

77. Datos obtenidos de MOYA VALGAÑóN, J. G., RUIZ-NAVARRO PÉREZ, J., ARRÚE UGARTE, B., Castillos y Fortalezas de La Rioja. Logroño, Caja de Ahorros de La Rioja, 1992, p. 146.

78. Datos obtenidos de SOMER, G. M., Proyecto básico de restauración del castillo fuerte de Herce y la organización de su entorno. Préjano, mayo 2005, inédito, a quien agradezco el haberme permitido su consulta, así como la utilización para este trabajo de los planos que lo ilustran.

79. SOMER, G. M., Ibidem. 


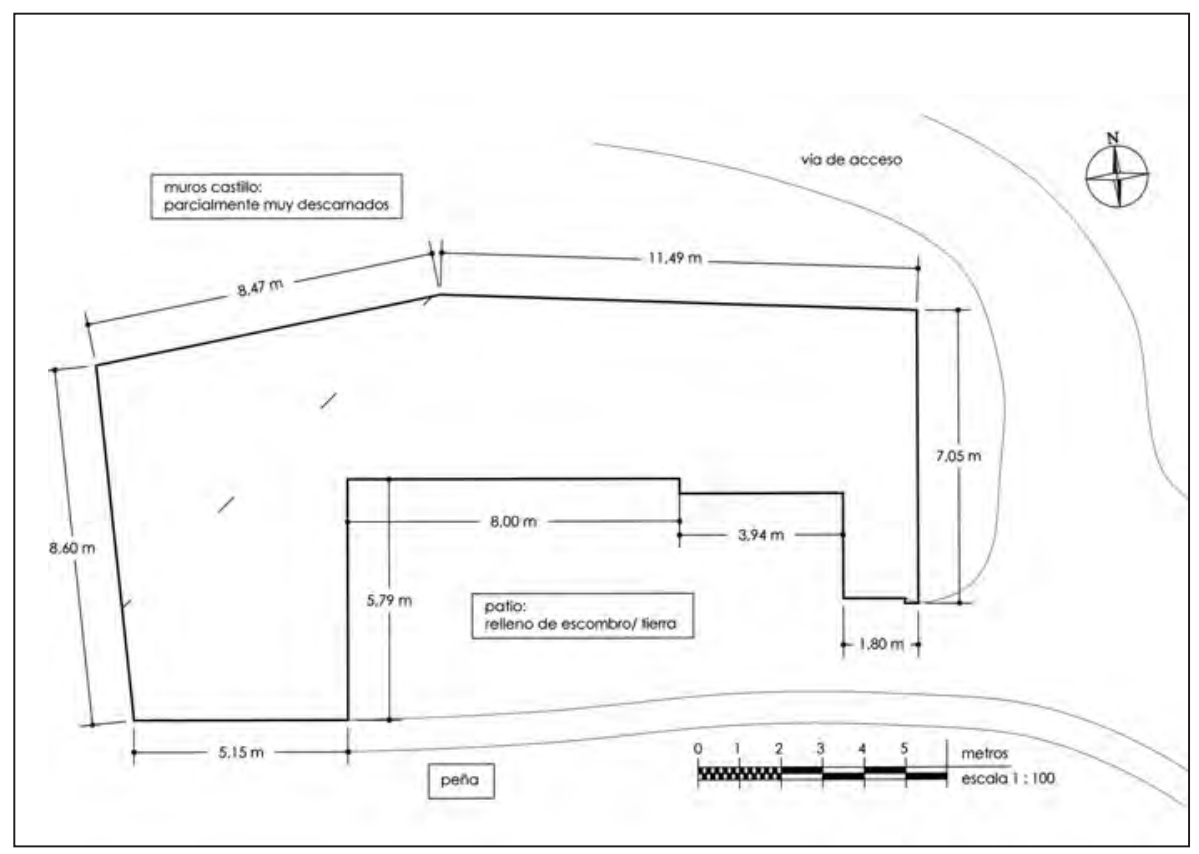

Figura 2. Planta baja del castillo de Herce. Plano de Georgina Martina Somer.

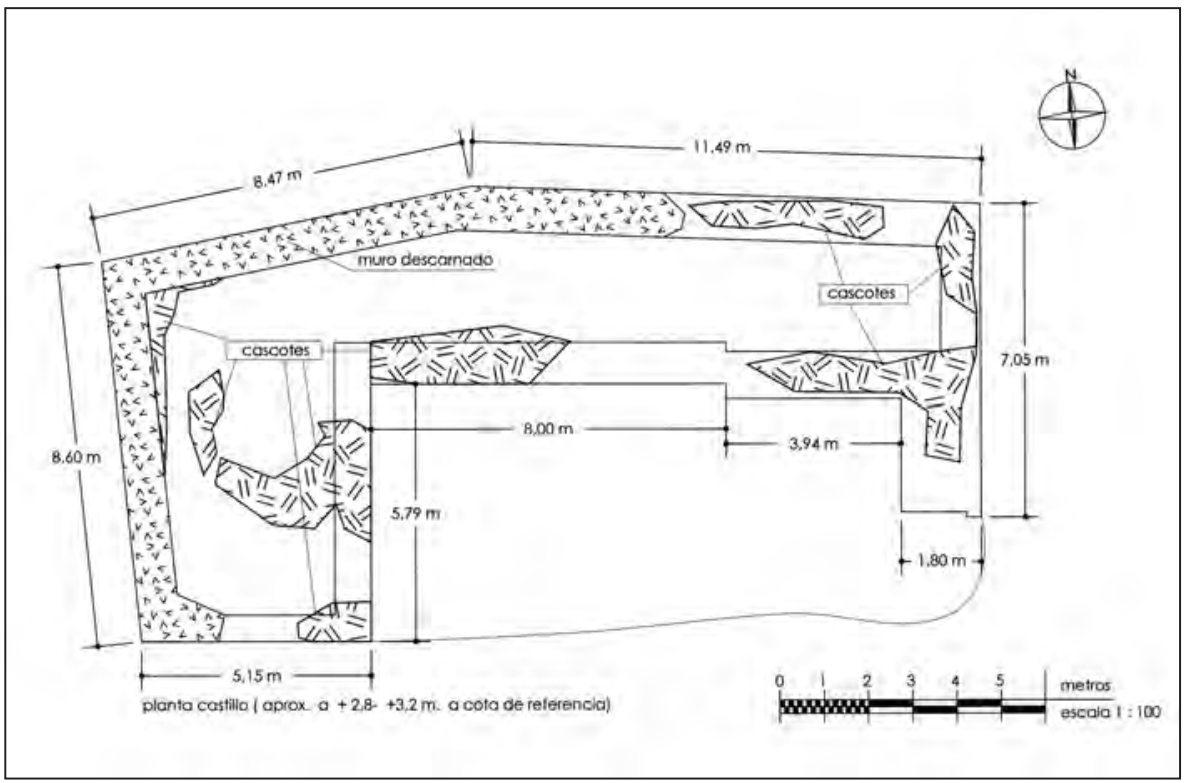

Figura 3. Planta del castillo de Herce. Plano de Georgina Martina Somer. 

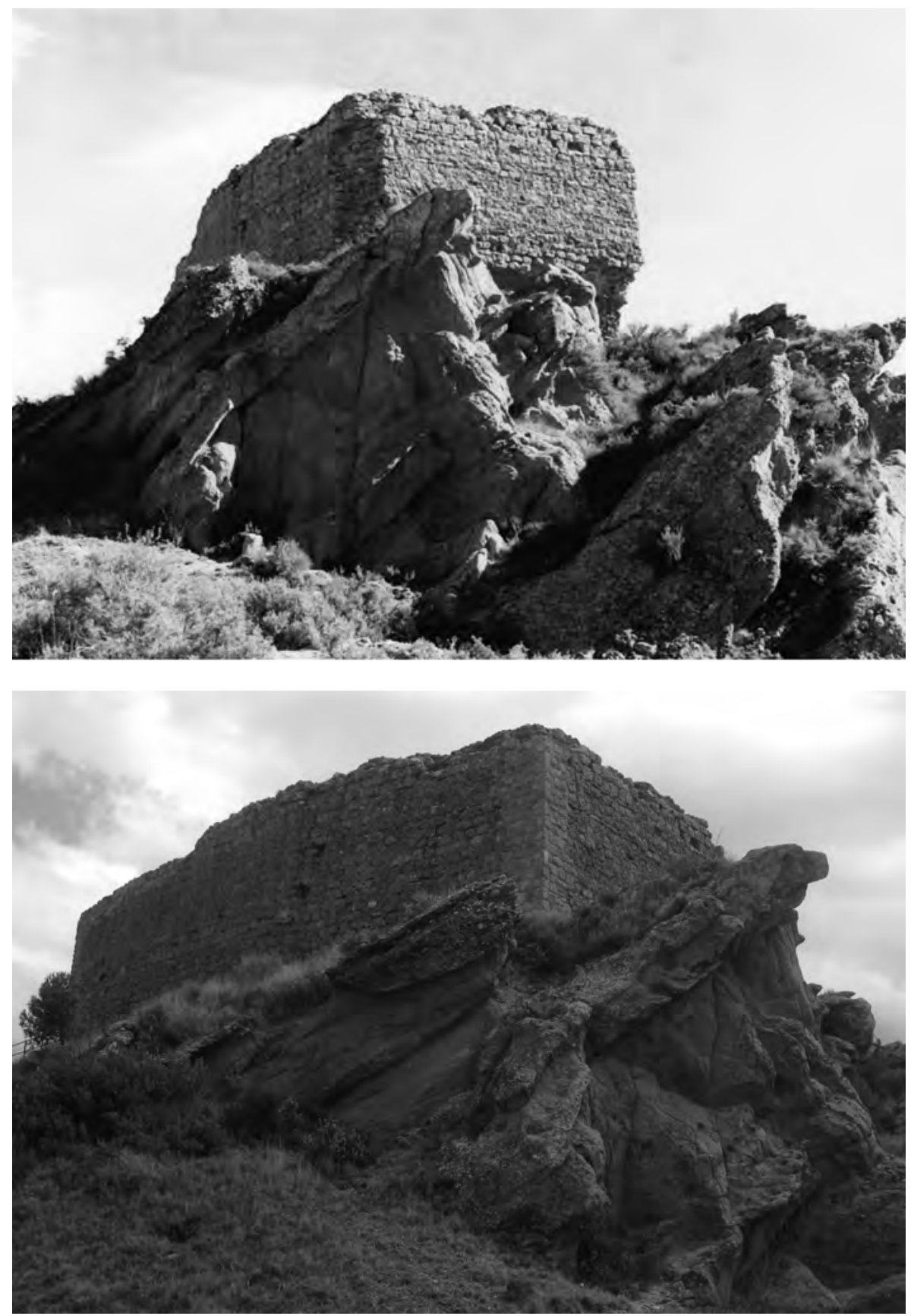

Láminas 11 y 12. Vertiente externa de los muros norte y oeste del castillo, antes de la restauración y después de la misma. 


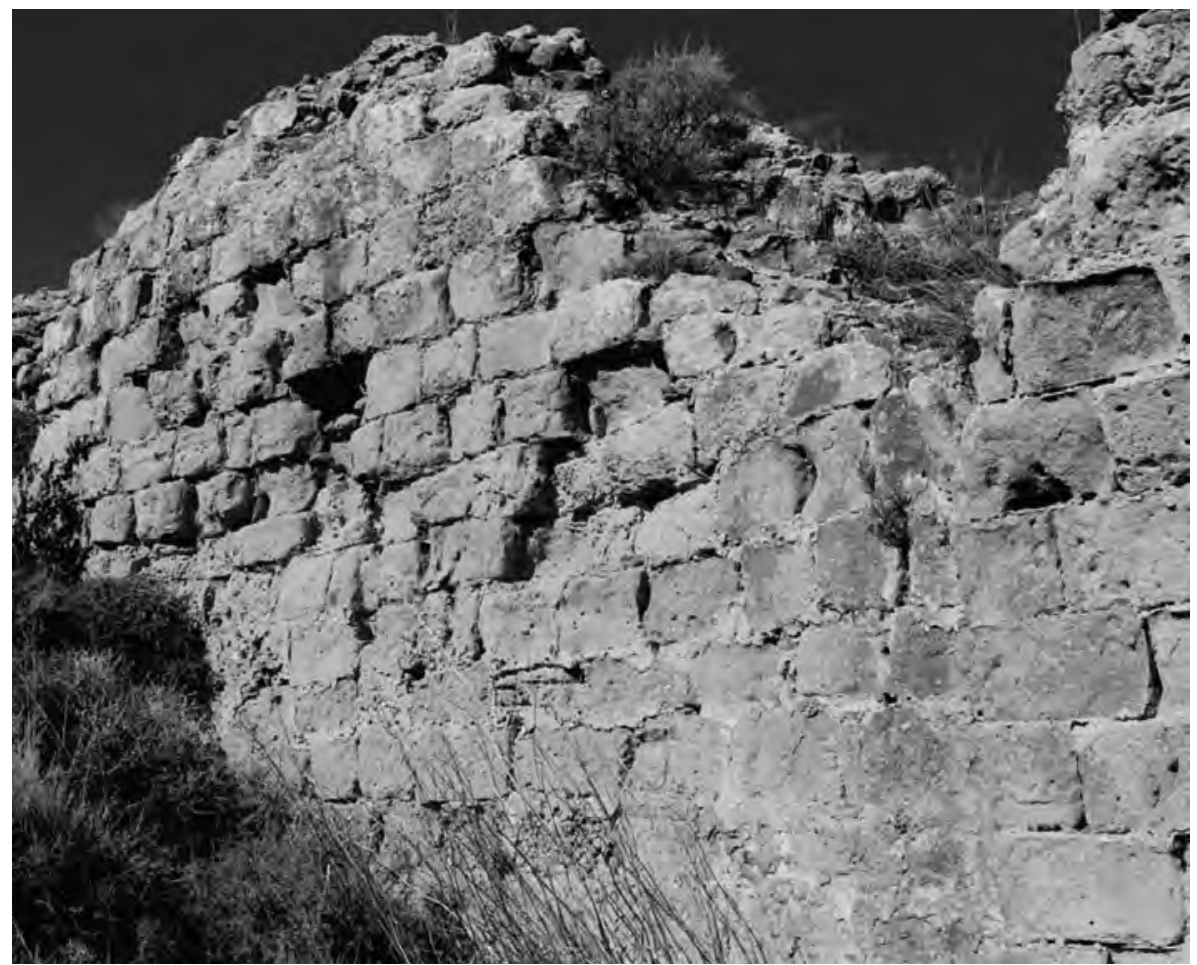

Lámina 13. Vertiente interna del muro norte en sillería.

En este muro oriental se situaba el ingreso, y tras las excavaciones arqueológicas se puede observar que el dintel de entrada tiene un orificio donde se insertaría el cerrojo o tranca de la puerta (Lám. 16). Se ha perdido la cubierta, pero junto al ingreso existen restos del arranque de una bóveda de cañón apuntado en el muro norte y el apeo de una bóveda de crucería en el mismo muro, a continuación de la bóveda de cañón citada (Láms. 14 y 15). Esto indica que el espacio interior de dicha torre constaba de dos ámbitos: el más oriental se cubriría con bóveda de cañón apuntado y el más occidental con bóveda de crucería sencilla. No deja de ser curiosa esta disposición similar a la de un pequeño templo con su cabecera y su nave, además orientado hacia el este, como es usual en las iglesias cristianas. De hecho, si las ruinas se contemplan aisladamente sin tener en cuenta el grosor de sus muros, la ausencia de vanos, su acceso por el este y su estratégica situación, podrían hacer sospechar que lo que queda aquí son los restos de una pequeña ermita o capilla de cabecera rectangular con bóveda de cañón apuntado y una nave más ancha cubierta con bóveda de crucería sencilla, tipología muy común en el arte rural románico y gótico de los siglos XII y XIII. 
EL CASTILLO DE HERCE EN EL VALLE DEL CIDACOS. UNA MIRADA HISTÓRICA-ARTíSTICA
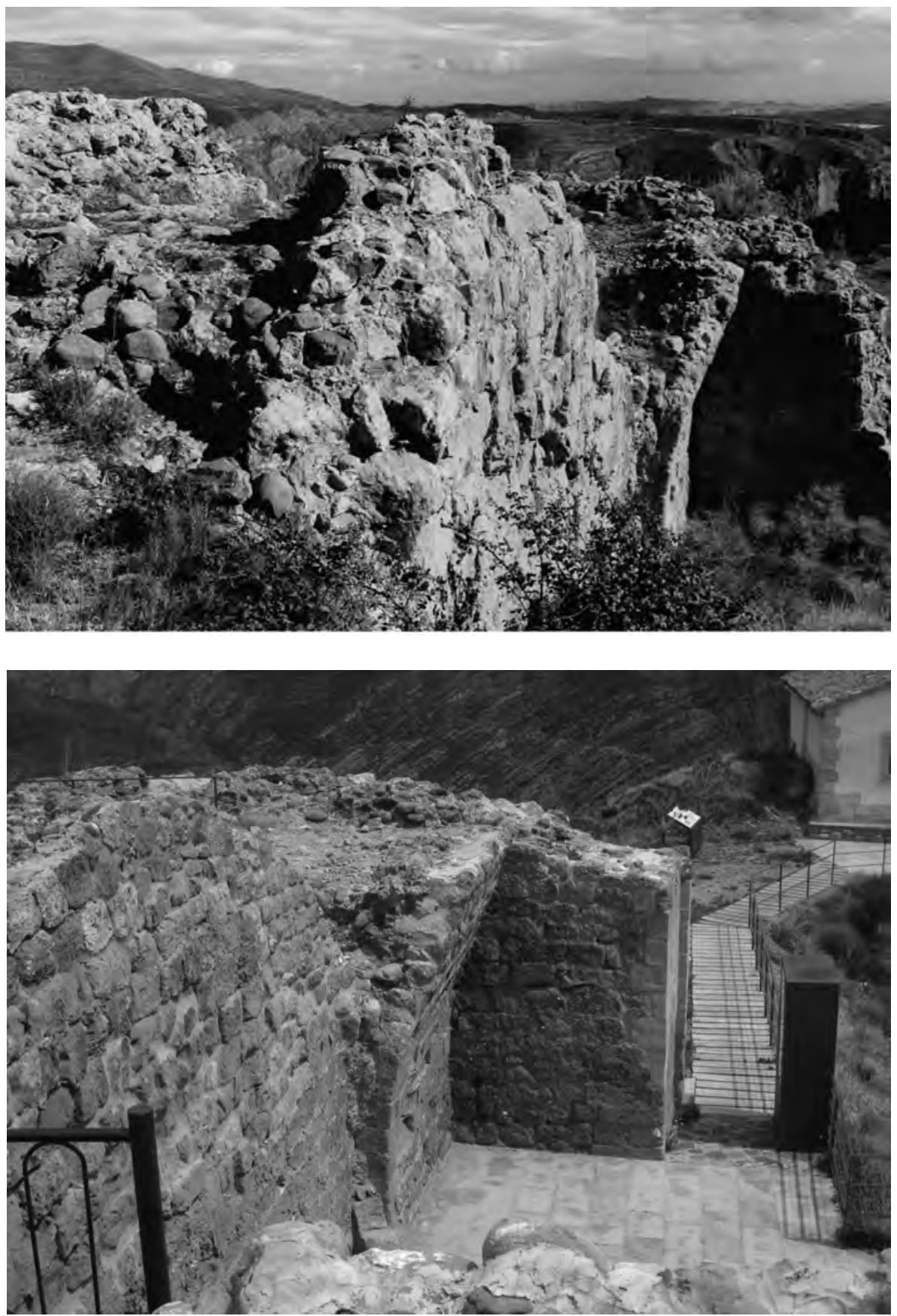

Láminas 14 y 15. Remate del muro norte hacia el oeste con el relleno de morrillo, y parte de la vertiente interior en sillería, antes y después de la restauración. 


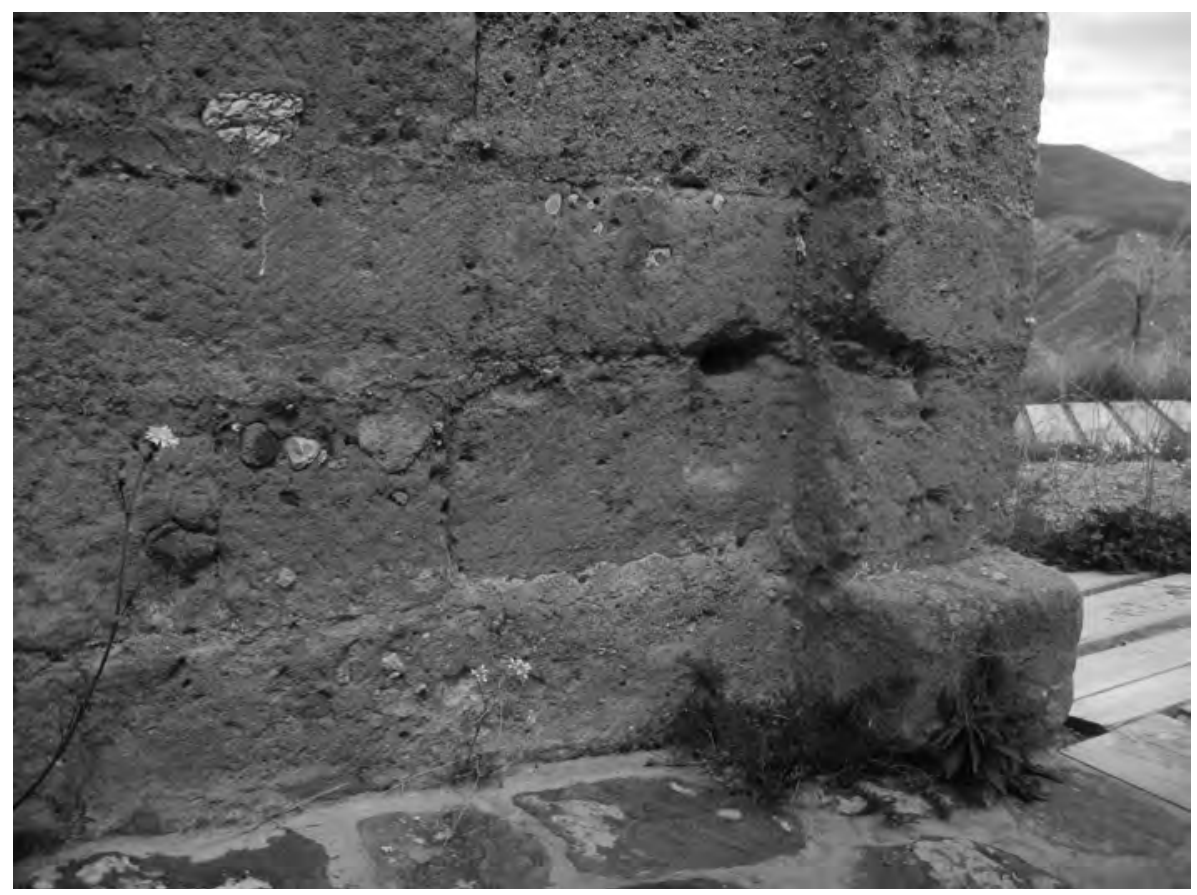

Lámina 16. Muro oriental donde estaba el ingreso, con orificio para el cerrojo o tranca.

No conserva forjados, pero en los muros norte y oeste hay tres mechinales o huecos para contener una estructura de vigas de madera que dividiera la torre en uno o varios pisos holladeros en su interior. Las excavaciones revelaron la existencia de un tosco basamento central para asentar un pilar de estructura interior (Láms. 17, 18). Vemos la curiosa coexistencia, en un ámbito tan reducido y próximo, de estructuras pétreas -bóvedas de cañón y crucería- con otras lígneas -vigas de madera que se encajaban en los mechinales del muro para soportar las distintas plantas. El acceso a estos pisos se realizaba en muchas ocasiones -como todavía se puede apreciar, por ejemplo, en los castillos de Clavijo o de Quel- con escaleras movibles de mano si no se disponía de escaleras fijas en husillo. (Láms. 19, 20).

El desmochamiento superior de la torre nos impide saber si se remataba con almenas. De hecho, no conserva ningún elemento defensivo (cubos, torreones circulares, cuadrados o poligonales, espolones triangulares, escaraguaitas en los ángulos, garitas o garitones volados, almenas o merlones, adarve, matacanes corridos, aspiIleras, saeteras, troneras, cadalsos, espacios entremuros, foso, etc.). La forma de los vanos (puertas, ventanas, aspilleras, saeteras, troneras...) nos habría ayudado en la datación, ya que su tipología va evolucionando al compás de los elementos de tiro: de los tipos rectos, sin derrame, hasta los abocinados, con derrame interior. 

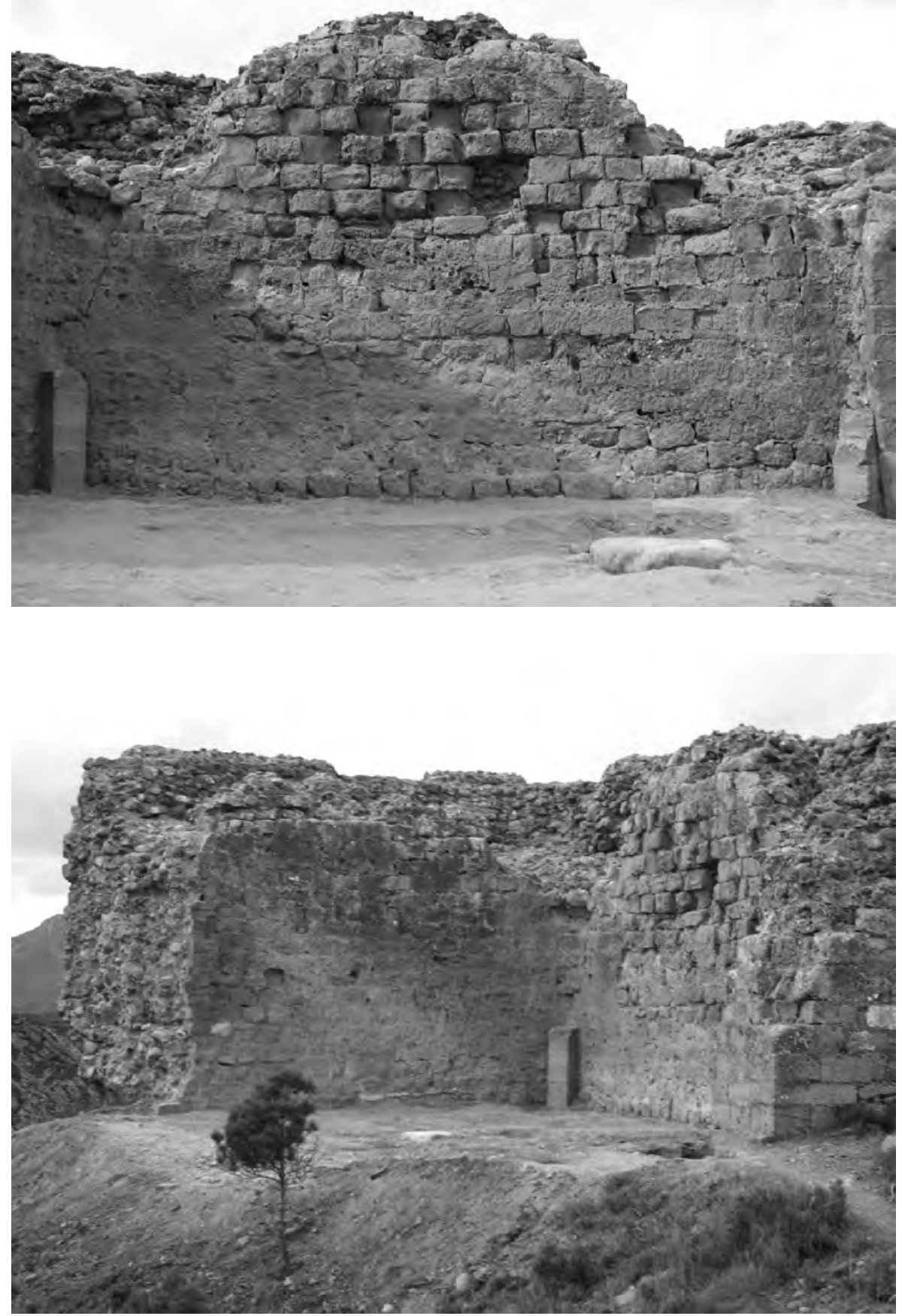

Láminas 17 y 18. Estado del castillo tras la excavación arqueológica. 

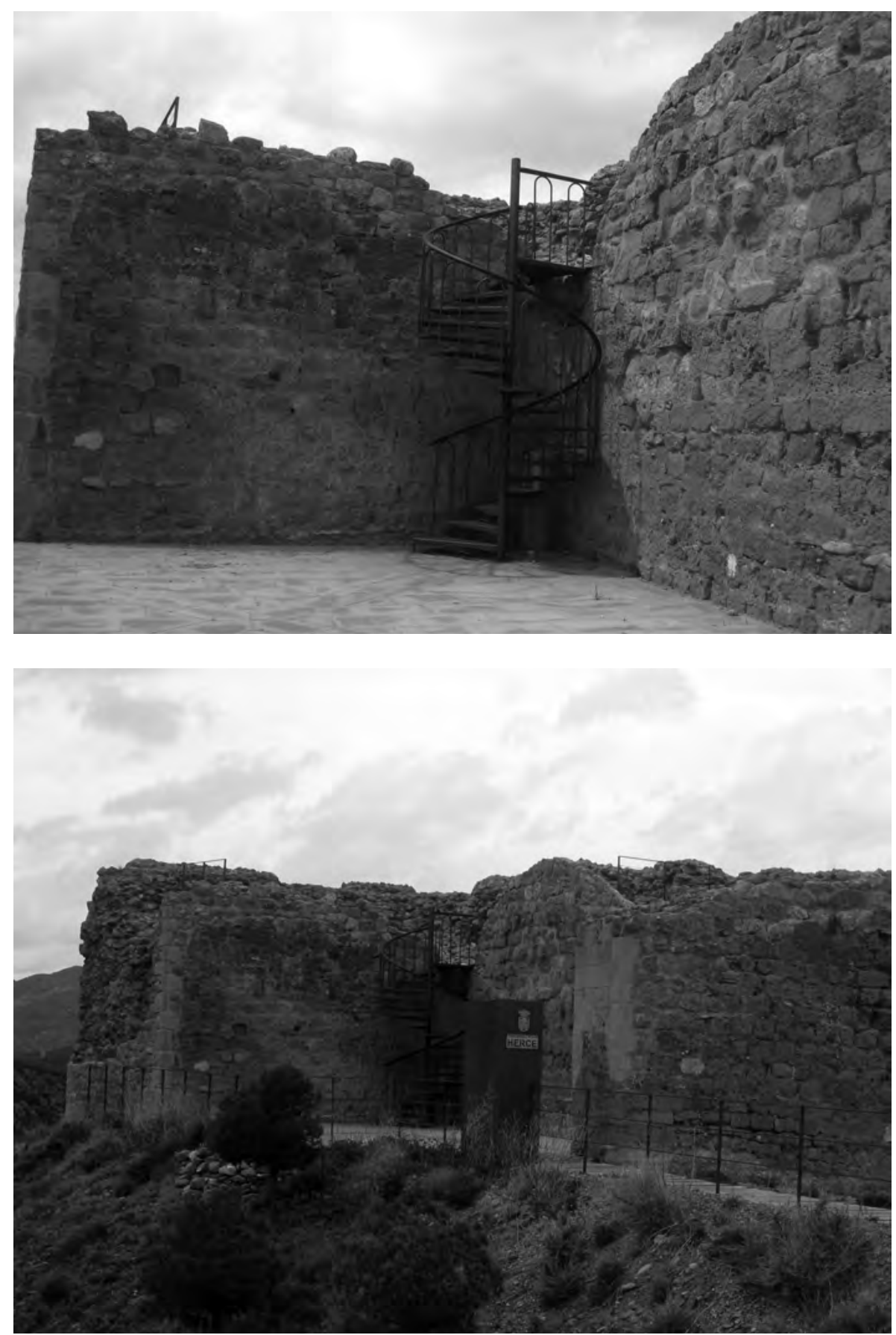

Láminas 19 y 20. Estado actual del castillo tras la intervención arquitectonica. 
A unos 50 ó $60 \mathrm{~m}$ de la torre hacia el noroeste, al lado de la vía de acceso al conjunto monumental, quedan vestigios de gruesos muros que sólo conservan el macizo interno de morrillo y que podrían pertenecer a una fortificación anterior, o bien constituir una barrera exterior de la torre que cerraría una explanada que se encuentra en un nivel más bajo que aquélla (Lám 21). En este ámbito aparecen rocas mezcladas con restos de muros de mampostería dibujando un recinto fortificado. La construcción a base de mampostería con mortero, argamasa o morrillo se adapta perfectamente a la topografía. Su desmochamiento superior también nos impide conocer si tenía remate almenado y adarve o si se reforzaba con torres en las esquinas o en el centro de los paramentos. Da la impresión de que la puerta de esta muralla, que permitiría el acceso a todo el conjunto, estaba situada en la parte norte del mismo, junto al actual camino.

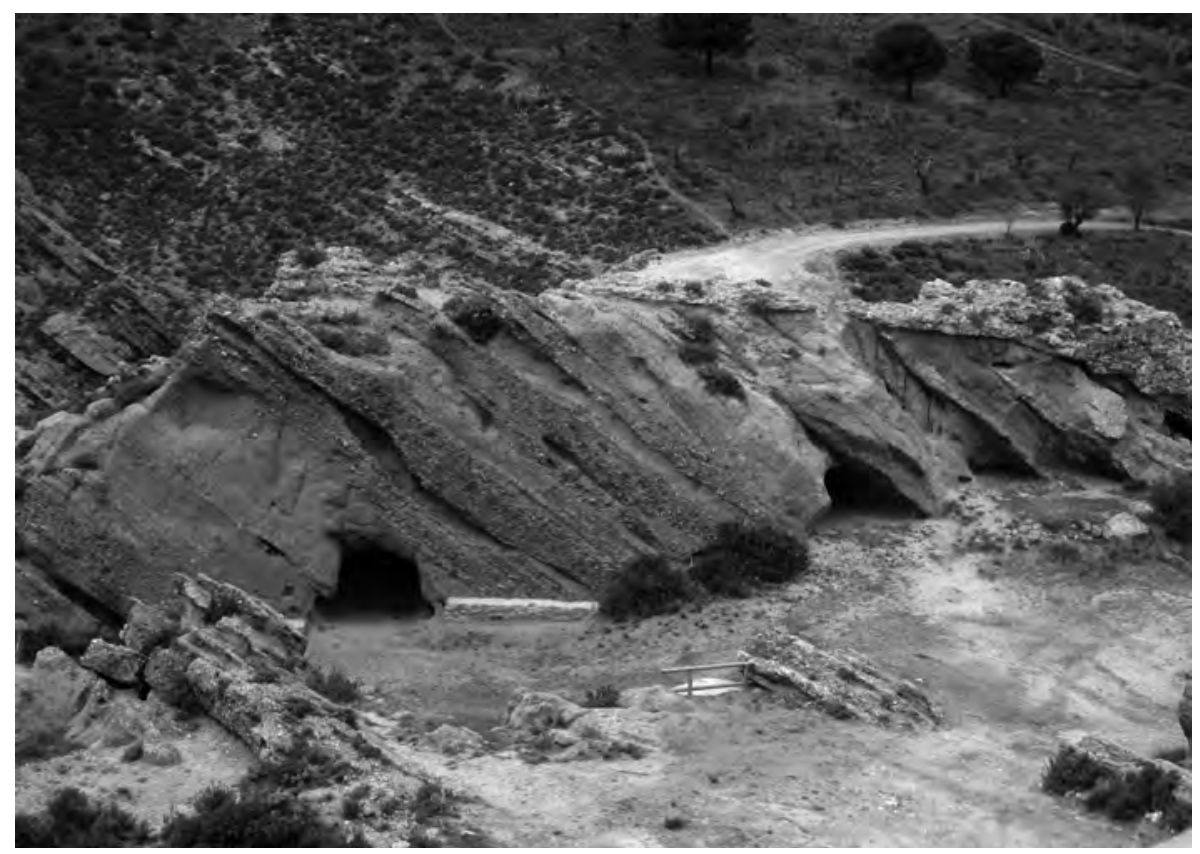

Lámina 21. Barrera defensiva exterior.

Las defensas naturales de la torre estarían constituidas, por tanto, por dos elementos: por el propio escarpe de la roca, que la hace inaccesible por su flanco meridional, y por esa barrera defensiva de la que hoy sólo quedan escasos restos, que protegería la zona septentrional, más accesible y vulnerable. Ciertamente esta construcción está ubicada en un enclave de gran importancia estratégica desde el que se aprecia gran parte del valle del Cidacos y de las montañas que lo rodean, como la Peña Isasa, Peñalmonte y la Sierra de Yerga (Lám. 4). 
En la vertiente interna de los muros defensivos, cuya parte inferior está constituida por la propia roca natural, existen dos pequeñas cuevas artificiales excavadas con bancos corridos en su interior, de las que no conocemos ni su cronología ni su función original, y que nos obligan a mencionar el tema de la arquitectura rupestre de la región. Los valles de los ríos Najerilla, Iregua, Jubera, Leza y Cidacos presentan una serie de escarpes o farallones casi cortados verticalmente, muy adecuados por sus blandos materiales (areniscas y conglomerados, arcillas y yesos, calizas) para ser excavados y abrir en ellos largas galerías; pero las que horadan los cortados del valle medio del Cidacos, en unos $10 \mathrm{~km}$ de longitud y en su orilla izquierda, desde Autol hasta Santa Eulalia Somera, a lo largo de la supuesta vía romana que unía Calahorra con Numancia, constituyen un conjunto excepcional por el gran número existente. En Herce, todas las paredes verticales del lado sur del cerro de El Salvador y de los otros cerros que dominan el pueblo están plagadas de cuevas; las hay en El Juncal (paraje Cuesta de Sarranco), Peña El Moro (paraje El Cueto), Barranco Higuerri (paraje Higuerri), Cabezo Redondo... ${ }^{80}$. Las denominadas cuevas palomares, donde hoy anidan diversos tipos de aves, se llaman en la localidad "farmacias de los moros". Todo este patrimonio rupestre destaca por constituir un paraje singular no sólo de interés histórico y etnográfico, sino de interés geomorfológico, cuyo valor ecológico ha supuesto su declaración como Reserva de la Biosfera.

80. Algunas de estas cuevas fueron inventariadas por HERNÁNDEZ DUQUE, F., MARTíNEZ-LOSA HERCE, Ma J., TRINCADO RUIZ, A., Inventario y clasificación tipológica de elementos rupestres de interés cultural en el valle medio del río Cidacos. 2001. Trabajo inédito incluido dentro del Inventario Arqueológico de La Rioja. Original conservado en la Consejería de Cultura del Gobierno de La Rioja. 